\title{
Modeling Monetary Policy
}

Samuel Reynard and Andreas Schabert

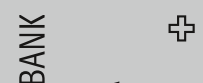

嵌出衫

岀岩这

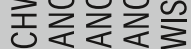

फळळळ थ 
The views expressed in this paper are those of the author(s) and do not necessarily represent those of the Swiss National Bank. Working Papers describe research in progress. Their aim is to elicit comments and to further debate.

\section{Copyright $\odot$}

The Swiss National Bank (SNB) respects all third-party rights, in particular rights relating to works protected by copyright (information or data, wordings and depictions, to the extent that these are of an individual character). SNB publications containing a reference to a copyright ( $\odot$ Swiss National Bank/SNB, Zurich/year, or similar) may, under copyright law, only be used (reproduced, used via the internet, etc.) for non-commercial purposes and provided that the source is mentioned. Their use for commercial purposes is only permitted with the prior express consent of the SNB.

General information and data published without reference to a copyright may be used without mentioning the source.

To the extent that the information and data clearly derive from outside sources, the users of such information and data are obliged to respect any existing copyrights and to obtain the right of use from the relevant outside source themselves.

\section{Limitation of liability}

The SNB accepts no responsibility for any information it provides. Under no circumstances will it accept any liability for losses or damage which may result from the use of such information. This limitation of liability applies, in particular, to the topicality, accuracy, validity and availability of the information.

ISSN 1660-7716 (printed version)

ISSN 1660-7724 (online version)

๑ 2010 by Swiss National Bank, Börsenstrasse 15, P.0. Box, CH-8022 Zurich 


\title{
Modeling Monetary Policy
}

\author{
Samuel Reynard ${ }^{1}$ \\ Swiss National Bank \\ Andreas Schabert \\ TU Dortmund University and University of Amsterdam
}

November 9, 2009

\begin{abstract}
We develop a macroeconomic framework where money is supplied against only few eligible securities in open market operations. The relationship between the policy rate, expected inflation and consumption growth is affected by money market conditions, i.e. the varying liquidity value of eligible assets and the associated risk. This induces a liquidity premium, which explains the observed systematic wedge between the policy rate and consumption Euler interest rate that standard models equate. It further implies a dampened response of consumption to policy rate shocks that is humpshaped when we account for realistic central bank transfers and the dynamics of bond holdings.
\end{abstract}

JEL classification: E52; E58; E43; E32.

Keywords: Monetary Policy; Open market operations; Liquidity premium; Money market rate; Consumption Euler rate; Monetary policy transmission.

\footnotetext{
${ }^{1}$ S. Reynard: Swiss National Bank, Research Unit, Boersenstrasse 15, 8022 Zurich, Switzerland. Phone: +41 44631 3216. Email: samuel.reynard@snb.ch. A. Schabert: University of Dortmund, Vogelpothsweg 87, 44227 Dortmund, Germany. Phone: +49 231755 3182. Email: andreas.schabert@udo.edu. The views expressed in this paper do not necessarily reflect those of the Swiss National Bank. We are grateful to Klaus Adam, Aleks Berentsen, John Cochrane, Matt Canzoneri, Bezhad Diba, Marty Eichenbaum, Jordi Gali, Max Gilman, Marvin Goodfriend, Dale Henderson, Pat Kehoe, James Nason, Stephanie Schmitt-Grohe, Frank Smets, Pedro Teles, Cédric Tille, as well as AEA 2009, BoP, Buba/CFS/ECB, CCBS-BoE, EEA 2009, Cleveland Fed, Gerzensee, IHEID, Konstanz, SNB, and SSES 2008 conference and seminar participants for useful comments.
} 


\section{Introduction}

In the last decades monetary policy has mainly been viewed as the science of controlling short-term interest rates and keeping inflation expectations in line with central bank targets. The current financial crises has however shifted attention towards the central banks' supply of money. In particular, an exceptionally large increase in the demand for liquidity has revealed that access to central bank money is actually constrained by the availability of scarce collateral. The fact that central banks typically supply money in exchange for eligible securities is not only relevant in times of crises, but also matters for asset pricing and macroeconomic effects of monetary policy in normal times, which will be shown in this paper.

We develop a macroeconomic model where money policy is modelled as an asset exchange, which is usually neglected in current macroeconomic theory. ${ }^{2}$ Accounting for the fact that only few securities are eligible for central bank transactions in open market operations provides a novel perspective on the relation between monetary policy, interest rates and real activity. The crucial property of the model is that monetary policy determines the liquidity of securities by declaring them as eligible or not. It is well-established from finance studies (e.g. Holmstrom and Tirole, 2001, Acharya and Pedersen, 2005) that differences in market liquidity of assets can affect pricing kernels. We contribute to this research by deriving a liquidity premium on interest bearing assets that originates in monetary policy implementation. We show that changes in the policy rate are not one-for-one passed through to all short-term interest rates, without introducing arbitrage opportunities. As a consequence, the effects of monetary policy on private savings and real activity differ from what standard models predict, where the rate of intertemporal substitution (and thus expectations of growth in the marginal utility of consumption) solely depends on the real policy rate.

The focus on short-term interest rate as central banks' operating targets in contemporary macroeconomic studies has been accompanied by the consumption Euler equation replacing money demand as the link between monetary policy and private sector behavior. By relating the policy rate to consumption growth and inflation, the consumption Euler equation governs monetary transmission. The widely known failure of Euler equations to explain the magnitude of risk-free interest rates (see Weil, 1989) has - until now - not been accounted for in mainstream macroeconomics, where the policy rate is usually assumed to equal the consumption Euler rate. However, recent studies report an even more worrying mismatch: the Euler rate implied by consumption and inflation data as well as its spread to short-term interest rates are both negatively related to the federal funds rate, while consumption and inflation seems to be much less volatile than implied by an Euler equation (see Canzoneri

\footnotetext{
${ }^{2}$ In small scale New Keynesian models, like Clarida et al.'s (1999) model or Woodford's (2003) textbook model, as well as in larger macroeconomic models, like Christiano et al.'s (2005) or Smets and Wouters' (2008) model, money is either omitted (assuming a cashless economy) or supplied via lump-sum transfers.
} 
et al., 2007, and Atkeson and Kehoe, 2009). This failure of the Euler equation casts severe doubts on the tight link between the monetary policy rate, consumption growth and inflation implied by standard models.

In this paper account for the implementation of monetary policy in a macroeconomic model and consider three interest rates: a repo rate for open market operations controlled by the central bank (the policy rate), an interest rate on short-term government bonds (the bond rate), and an interest rate on private debt (the debt rate or Euler rate). The model can generate a substantial spread between the debt rate and the bond rate, i.e. a liquidity premium, ${ }^{3}$ and a small spread between the bond rate and the policy rate, i.e. a pure risk premium. The focus of our analysis is on the liquidity premium, which contributes to explaining the risk-free-rate puzzle and the above mentioned Euler rate correlations. ${ }^{4}$ Specifically, the liquidity premium varies endogenously with the expected costs of transforming bonds into means of payment. Consistent with empirical evidence, we show that the liquidity premium and the Euler rate can be negatively related to the policy rate. At the same time, the impact of a rise in the policy rate on aggregate demand and inflation is dampened compared to standard models (where the central bank sets the Euler rate), while the consumption response is hump shaped.

The model mainly differs from a standard macroeconomic model by three assumptions: first, we assume that financial markets are separated. The asset market, where agents trade interest bearing assets and cash, opens at the end of each period. Before, the money market opens, where agents can acquire cash from the central bank in exchange for eligible securities discounted with the rate set by the central bank, i.e., the policy rate. Eligible securities that are bought today can be cashed in the next period at the policy rate. The bond rate is therefore closely linked to the expected future repo rate in open market operations, while the spread between these rates increases on average with aggregate uncertainty and investors' relative risk aversion. Thus, the bond rate and the policy rate differ due to a risk premium.

Second, we consider central banks' practice (like the Fed's or the BoE's in normal times) and assume that only short-term government bonds are eligible in open market operations, while other - especially privately issued - debt securities cannot be cashed in at the central bank. ${ }^{5}$ The crucial property is that the amount of eligible assets is not unlimited. Access

\footnotetext{
${ }^{3}$ Other macroeconomic studies that have derived a liquidity premium for bonds include Bansal and Coleman (1996), Lagos (2006), Canzoneri, Cumby and Diba (2007), and Goodfriend and McCallum (2007).

${ }^{4}$ Aiyagari and Gertler (1991) and Eisfeldt (2007) conclude that the demand for short-term treasury securities (T-bills) cannot solely be explained with consumption smoothing, and suggest considering a transactions demand for liquid assets.

${ }^{5}$ This assumtion, which has also been made by Lacker (1997) for the anaylsis of different payment system tools, accords to the Fed's asset aquisition policy before the recent financial crises. In 2006, for example, Treasury bills were the largest position accounting for one-third of the System Open Market Account (SOMA) holdings. Bills and Treasury coupon securities with a maturity below 2 years accounted for about two-third of SOMA holdings, while treasury securities of longer maturities and a relatively small amount of Treasury
} 
to money is thus bounded by private sector government bond holdings and cannot be eased by holding other assets. Due to this property, government bonds are perceived as a closer substitute for cash, which gives rise to a liquidity premium. ${ }^{6}$ Thus, in equilibrium we can observe a spread between the bond rate and the interest rate on privately issued debt. The debt rate, which corresponds to the above mentioned consumption Euler rate, thus differs from the bond rate (and thus the policy rate), while the spread depends on the state of the economy. In particular, a higher policy rate raises the price of money in terms of bonds, i.e. reduces the amount of money per unit of bonds supplied to the central bank, and therefore leads to a decline in the liquidity premium, consistent with Canzoneri et al.'s (2007) and Atkeson and Kehoe's (2009) findings.

Third, we assume, in line with central bank practice (see e.g. Meulendyke, 1998), that the central bank reinvests payoffs from maturing securities in new assets. The associated interest earnings are then transferred to the fiscal authority, while financial wealth is held by the central bank as the counterpart of outstanding money. ${ }^{7}$ As a consequence, the distribution of eligible securities between the private sector and the central bank changes over time and, in particular, varies with the monetary policy stance. This property leads to an additional effect of monetary policy on the private sector behavior, specifically, a hump-shaped consumption response to monetary policy shocks.

We find that monetary transmission is substantially affected by these assumptions, in particular, when the constraint in open market operations ("discounted value of bonds held by the private sector $\geq$ new money") is binding. ${ }^{8}$ Consider, for example, an unexpected increase in the policy rate, i.e. a positive innovation to a Taylor-type feedback rule for the policy rate. Aggregate demand is constrained by the amount of short-term bonds discounted with the policy rate (plus money carried over from the previous period), which represents the amount of money the private sector can get through open market operations. Hence, a higher policy rate has a negative effect on nominal consumption and - due to imperfectly flexible prices - also on real consumption. ${ }^{9}$ Monetary policy thereby impacts on the level of real consumption rather than on its growth rate, as implied by standard models. When the

\footnotetext{
inflation-indexed securities completed the porfolio.

${ }^{6}$ To be more precise, there are two interest rate differentials due to the liquidity of assets: $i$.) the spread between the rates of return on money and government bonds, and ii.) the spread between the rates of return on private debt and bonds. The liquidity premium in Kiyotaki and Moore (2008), for example, equals the difference between the expected return on (partially re-saleable) equity and money, and thus relates to $i$.). Throughout the paper, we will focus on $i i$.).

${ }^{7}$ This differs from the common assumption in general equilibrium macro-models that the central bank transfers seigniorage (defined as the change in the monetary base) to the fiscal authority.

${ }^{8}$ In this case, where other assets offer a higher interest rate, household economize on holdings of bonds and hold bonds only for transaction purposes. This property is for example consistent with Eisfeldt's (2007) results. Calibrating a model to match US data, she shows that intertemporal consumption decisions can contribute to explaining the demand for short-term T-bills only to an extremely small extent.

${ }^{9}$ For the analysis of the monetary transmission mechanism we consider sticky prices to account for realistic inflation dynamics.
} 
central bank increases its policy rate, part of that increase reflects a decrease in the liquidity premium such that the effects on consumption growth and inflation are dampened compared to a standard model.

Moreover, due to the third assumption (see above), the rise in the policy rate further affects consumption through its impact on the distribution of eligible securities. If, for example, monetary policy is tightened by an inertial increase of the policy rate, the central bank demands more bonds in exchange for money. With reduced bond holdings, the open market constraint tends to become even tighter in the next period, leading to a hump-shaped decline in consumption. Hence, an unexpected increase in the policy rate can lead to a decline in the consumption growth rate, which - together with lower expected inflation - implies the Euler-rate to fall, consistent with empirical evidence.

The analysis further shows that a higher ratio of money supplied under repurchase agreements relative to money supplied outright increases the effectiveness of changes in the policy rate, which provides an argument for central banks to create a "structural deficiency" with respect to the outright supply of money, like the Fed. ${ }^{10}$ Finally, we expect the model developed in this paper to contribute to the solution of the so-called liquidity puzzle and to serve as an ideal framework for the analysis of unconventional policy options at the zero lower bound (ZLB) on interest rates.

The paper is organized as follows. Section 2 presents empirical evidence on short-term interest rates and spreads. In section 3, the model is developed. In section 4 , we examine the behavior of interest rates and spreads in the model. Section 5 presents quantitative results and discusses the monetary transmission mechanism. Section 6 concludes.

\section{Empirical evidence}

This section examines the empirical behavior of different interest rates that will be considered in the model and the relationships between them. We will consider an Euler rate $R^{\text {Euler }}$ (or $R^{d}$ ) i.e., the rate implied by the consumption Euler equations, a policy rate $R^{m}$, i.e. the price of money in terms of bonds in open market operations, and an interest rate $R$ on an asset that the central bank accepts in exchange for money in its open market operations. These two interest rates, $R^{m}$ and $R$, evidently correspond to the federal funds rate and to the t-bill rate. The interest rate $R$ can alternatively be interpreted in our model as the price of money (in terms of bonds) outside open market operations. Hence, one might also consider the US\$-libor rate as an interest rate that corresponds to $R$. In both cases, t-bill or libor rate, the average spread to the federal funds rate is very small, and usually a few basis points below or above zero.

\footnotetext{
${ }^{10}$ See "Fedpoint: Open Market Operations", http://www.newyorkfed.org/aboutthefed/fedpoint/fed32.html).
} 
Given that empirically and in the model both $R^{m}$ and $R$ move relatively close to each other and contrast significantly with the behavior of $R^{\text {Euler }}$, we disregard the difference between $R^{m}$ and $R$ for the empirical analysis. To facilitate comparisons with related studies, we will focus on the spread between the federal funds rate and the Euler rate in this section. First, the empirical interest rate implied by standard Euler equations is computed. The methodology is similar to Fuhrer (2000) and Canzoneri et al. (2007). According to a standard Euler equation, the (gross) Euler rate $R_{t}^{\text {Euler }}$ satisfies

$$
\frac{1}{R_{t}^{E u l e r}}=\beta E_{t}\left(\frac{u_{c, t+1}}{u_{c, t}} \frac{P_{t}}{P_{t+1}}\right)
$$

where $\beta$ is the discount factor, $u_{c}$ is marginal utility of consumption, and $P$ is the price level. With a standard CRRA utility function, leading to a marginal utility of consumption $u_{c, t}=c_{t}^{-\sigma}$, and under conditional log-normality the Euler equation can be written as

$$
\frac{1}{R_{t}^{\text {Euler }}}=\beta \exp \left[\begin{array}{c}
-\sigma\left(E_{t} \log c_{t+1}-\log c_{t}\right)-E_{t} \log \pi_{t+1} \\
+\frac{\sigma^{2}}{2} \operatorname{var}_{t} \log c_{t+1}+\frac{1}{2} \operatorname{var}_{t} \log \pi_{t+1}+\sigma \operatorname{cov}_{t}\left(\log c_{t+1}, \log \pi_{t+1}\right)
\end{array}\right],
$$

where $\pi_{t}=P_{t} / P_{t-1}$. Equation (2) is used to compute the implied standard (net) Euler interest rate $r_{t}^{\text {Euler }}=R_{t}^{\text {Euler }}-1$, where the conditional moments are estimated from a sixvariable VAR, $Y_{t}=A_{0}+A_{1} Y_{t-1}+v_{t}$, assuming $v \sim$ i.i.d.N $(0, \Sigma), \sigma=2$ and $\beta=.993$. The variables included in $Y$ (1966Q1-2008Q2) are log per capita real personal consumption expenditures on nondurable goods and services, log change in the deflator of this consumption measure, log price of industrial commodities, log per capita real disposable personal income, federal funds rate $r_{t}^{m}=R_{t}^{m}-1$, and log per capita real non-consumption GDP. ${ }^{11}$ Moreover, a segmented (1974Q1) time trend is included in $A_{0}$.

Figure 1 displays the computed standard Euler interest rate and the federal funds rate, as well as the spread between these two rates, $s_{t}^{\text {Euler,m }}=R_{t}^{\text {Euler }}-R_{t}^{m}$, in percent. The Euler rate $r_{t}^{\text {Euler }}$ averages at 11.4 percent, whereas the federal funds rate $r_{t}^{m}$ averages at 6.5 percent; thus the average spread is 4.9 percentage points. Inflation averages at 4.4 percentage points over the period considered. The federal funds rate and the Euler rate, which should be identical according to standard macroeconomic models, display no apparent co-movement. The federal funds rate is strongly negatively correlated with the spread, a fact that has recently been pointed out by Atkeson and Kehoe (2009), while using Smets and Wouter's (2007) model. Thus, the unexplained wedge between the federal funds rate and the Euler rate is substantially related to the federal funds rate.At low frequency, the Euler and federal funds rates are positively correlated, which is mainly due to inflation trends (upward in the

\footnotetext{
${ }^{11}$ Quarterly data are from the Federal Reserve Bank of St. Louis FRED database and are released by the Federal Reserve Board, the Bureau of Economic Analysis (U.S. Department of Commerce), the Bureau of Labor Statistics (U.S. Department of Labor), and the Census Bureau (U.S. Department of Commerce).
} 


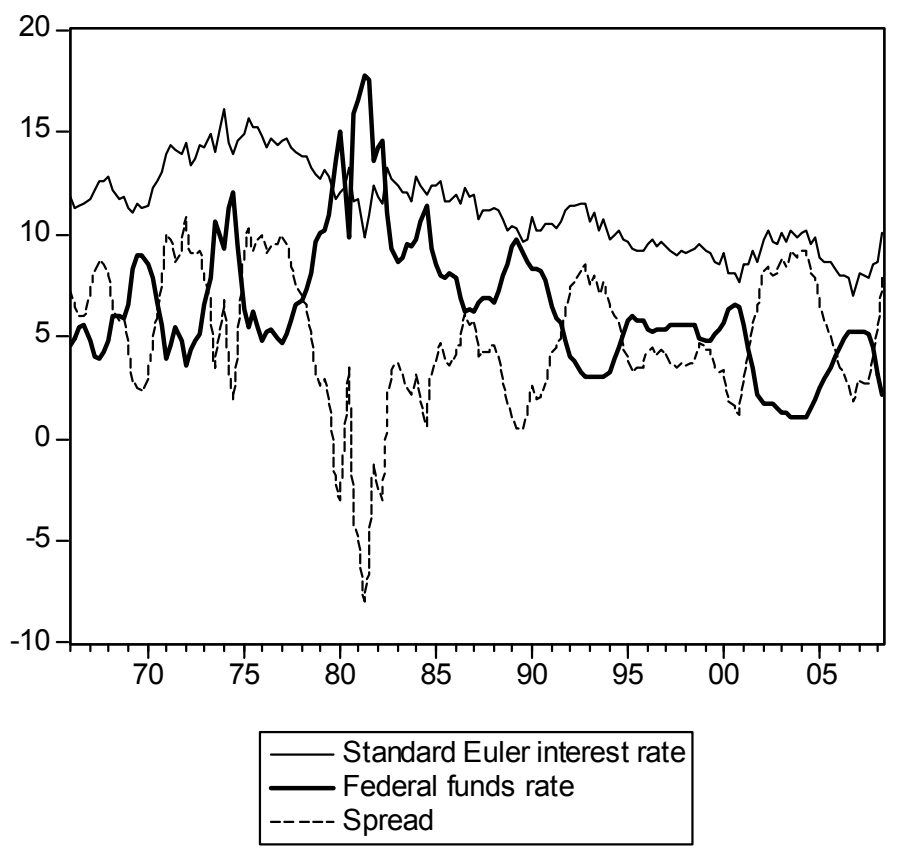

Figure 1: Euler rate $r^{\text {Euler }}$ and federal funds rate $r^{m}$ (in \%)

1970s and then downward in the 1980s) that move both rates in the same direction. These trends evidently distort the correlation between the Euler and policy rates in comparison to a theoretical environment with constant steady-state inflation. In order to correct for these inflation trends and to isolate short-run (business cycle) interest rate dynamics from longer term movements, we HP-filter $(\lambda=1600)$ the interest rate series. The correlations between HP-filtered variables will be used to assess theoretical moments of our model, which will be computed for a fixed steady-state inflation rate.

Table 1 Empirical correlations for HP-filtered series

\begin{tabular}{cccc}
\hline \hline Euler rate & \multicolumn{2}{c}{ Debt rate } \\
\hline $\operatorname{corr}\left(s_{t}^{\text {Euler }}, R_{t}^{m}\right)$ & -0.98 & $\operatorname{corr}\left(s_{t}, R_{t}^{m}\right)$ & -0.90 \\
$\operatorname{corr}\left(R_{t}^{\text {Euler }}, R_{t}^{m}\right)$ & -0.66 & $\operatorname{corr}\left(R_{t}^{d}, R_{t}^{m}\right)$ & -0.57 \\
\hline \hline
\end{tabular}

Figure 2 displays the same variables as in Figure 1 but HP-filtered. The bold line is minus the detrended federal funds rate. Thus, there is an apparent negative comovement between fluctuations of the spread and of the policy rate. Moreover, the Euler and policy rates are also negatively correlated at business cycle frequency. Table 1 presents the correlations for the HP-filtered series, i.e., the (unconditional) correlations between the federal funds rate, the Euler rate, and the spread $s^{\text {Euler,m }}$ (left column). The table further contains correlations 


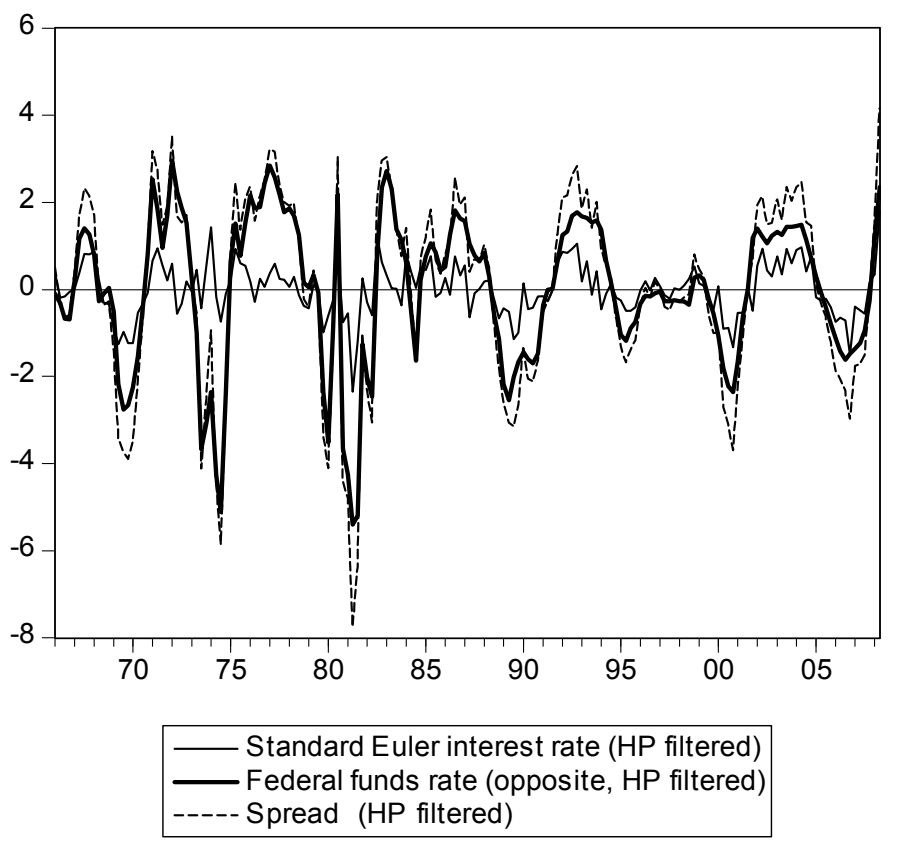

Figure 2: HP-filtered Euler rate $r^{\text {Euler }}$ and federal funds rates $r^{m}$ (in \%)

in terms of the closely related debt rate $R_{t}^{d}$ (and $s_{t}^{m}=R_{t}^{d}-R_{t}^{m}$ ), which corresponds to the Euler rate in our model. ${ }^{12}$ Three main results should be noted: first, there is a strong negative correlation (close to minus one) between the spreads and the policy rate. Second, the Euler (debt) rate and the policy rate are negatively correlated as well, though to a smaller extent than the spreads. ${ }^{13}$ Third, the correlations for the Euler rate and the debt rate are relatively similar.

As emphasized by Atkeson and Kehoe (2009), the apparent mismatch between the Euler and federal funds rates casts severe doubts on the common practice in current macroeconomics to assume that both rates are identical. We will show in the subsequent sections that this behavior of interest rates can be explained by modeling monetary policy in accordance with central bank practice.

\footnotetext{
${ }^{12}$ Details on this latter rate can be found in the subsequent section and in appendix 8.2. The difference between the standard Euler equation and the Euler equation in our model is mainly due to a cash-in-advance constraint. Overall, these two rates differ only slightly, except in accelerating inflation (late 1970s) and disinflation (early 1980s) episodes, as well as around 1992 and 2003 with the drops in the policy rate.

${ }^{13}$ This relates to the results in Canzoneri et al. (2007) for the case of real rates. Their correlation between real rates is smaller than the values given in our table 1 , and they find a positive correlation between nominal rates, which is due to the inflation trends, as explained above.
} 


\section{$3 \quad$ The model}

In this section we develop a macroeconomic framework where the asset market and open market operations (the money market) are separated. There are four different types of agents: households, firms, the central bank and the government. We abstract from financial intermediation and assume that households directly trade with the central bank in open market operations.

Households can hold short-term government bonds (i.e. T-bills) and non-interest bearing money, and they can borrow and lend among each other using a full set of nominally state contingent claims. Their demand for money is induced by assuming that goods market transactions cannot be conducted by using credit. This is modelled by a cash-in-advance constraint, i.e. by assuming that households have to hold money for goods market purchases. They can get money from the central bank only in exchange for eligible securities in open market operations. To give a preview, financial markets separation will lead to a spread between the government bond rate and the policy (repo) rate, i.e. a risk premium, whereas the spread between the debt rate and the bond rate, i.e. a liquidity premium, will be due to the special role of government bonds in open market operation.

Throughout the paper, upper case letters denote nominal variables, lower case letters real variables, and variables without an index $(i$ or $j$ ) aggregate variables.

\subsection{Timing of events}

The timing of markets and the specification of open market operations will be important for our results. We will focus on the case where only government bonds are eligible in open market operations. The timing of events in each period is as follows:

A household $i$ enters a period $t$ with nominal assets carried over from the previous period $t-1$ :

$$
M_{i, t-1}^{H}+B_{i, t-1}+D_{i, t-1}
$$

where $M^{H}$ denotes holdings of money, $B$ one-period government bonds, and $D$ oneperiod state privately issued contingent claims.

1. Aggregate shocks materialize, labor is supplied by households, and goods are produced by firms.

2. Households can then trade money in exchange for eligible assets in open market operations. The central bank supplies via outright sales/purchases and via repurchase agreements. The relative price of money $R_{t}^{m}$ (for both types of trades) is controlled by the central bank and will be called policy (or repo) rate:

$$
\Delta B_{i, t}^{c} / R_{t}^{m}=I_{i, t}
$$


where $I_{i, t}$ is the amount of money received by household $i$ and $\Delta B_{i, t}^{c}$ the amount of bonds the central bank gets. We assume that only government bonds are eligible

$$
\Delta B_{i, t}^{c} \leq B_{i, t-1}
$$

When household $i$ leaves the money market, its bond holdings equal $B_{i, t-1}-\Delta B_{i, t}^{c}$.

3. Households enter the (final) goods market, where money is assumed to be the only accepted means of payment. Thus goods market expenditures are constrained by money carried over from the previous period plus money acquired from the central bank in current period open market operations:

$$
P_{t} c_{i, t} \leq I_{i, t}+M_{i, t-1}^{H},
$$

where $c_{i}$ denotes purchases of the final consumption good and $P$ its price level. When household $i$ leaves the goods market, its money stock equals $I_{i, t}+M_{i, t-1}^{H}-P_{t} c_{i, t}$.

4. Before households trade in the asset market, current labor income and dividends are paid back in cash to households. Further, government bonds can be repurchased from the central bank with cash, i.e. household $i$ can repurchase bonds $B_{i, t}^{R}$ using money $M_{i, t}^{R}=B_{i, t}^{R}$. After repurchase agreements are settled, money and bond holdings of household $i$ equal

$$
\begin{aligned}
\widetilde{M}_{i, t} & =I_{i, t}+M_{i, t-1}^{H}+P_{t} w_{t} n_{i, t}+P_{t} \delta_{i, t}-P_{t} c_{i, t}-M_{i, t}^{R}, \\
\widetilde{B}_{i, t} & =B_{i, t-1}-\Delta B_{i, t}^{c}+B_{i, t}^{R},
\end{aligned}
$$

where $w_{t}$ denotes the real wage rate, $n_{t}$ working time and $P_{t} \delta_{i, t}$ dividends.

5. Finally, the asset market opens. In the asset market, households receive payoffs from maturing debt. They can further borrow/lend and trade money and bonds among each other, and they can buy bonds from the government at the price $1 / R_{t}$ (while the price of money in terms of bonds in the asset market equals $R_{t}$ ). Hence, we can summarize the asset market constraint of household $i$ as

$$
\left(B_{i, t} / R_{t}\right)+E_{t}\left[q_{t, t+1} D_{i, t}\right]+M_{i, t}^{H} \leq \widetilde{B}_{i, t}+D_{i, t-1}+\widetilde{M}_{i, t}+P_{t} \tau_{t}
$$

where $P_{t} \tau_{t}$ denotes lump-sum government transfers and $q_{t, t+1}$ is a stochastic discount factor, which will be defined below. The central bank reinvests its payoffs from maturing bonds in new bonds and does not change money supply. Since money cannot be issued by the private sector, $\int \widetilde{M}_{i, t} d i=\int M_{i, t}^{H} d i$ holds.

The total amount of government bonds held by the private sector at the end of the period $\int B_{i, t} d i$ will depend on how many bonds are issued by the fiscal authority and held by the 
central bank. In what follows we describe the model in detail.

\subsection{Private sector}

Households There is a continuum of infinitely lived households indexed with $i \in[0,1]$. Households have identical asset endowments and identical preferences. Household $i$ maximizes the expected sum of a discounted stream of instantaneous utilities $u$ :

$$
E_{0} \sum_{t=0}^{\infty} \beta^{t} u\left(c_{i t}, n_{i t}\right),
$$

where $E_{0}$ is the expectation operator conditional on the time 0 information set, and $\beta \in$ $(0,1)$ is the subjective discount factor. The instantaneous utility $u$ is assumed to satisfy $u_{t}=\left[\left(c_{i, t}^{1-\sigma}-1\right)(1-\sigma)^{-1}\right]-\gamma n_{i, t}$, where $\sigma \geq 1$ and $\gamma>0$.

A household $i$ is initially endowed with money $M_{i,-1}^{H}$, government bonds $B_{i,-1}$, and privately issued debt $D_{i,-1}$. As described above, it faces three constraints in each period. In open market operations, it can acquire additional money $I_{i, t}$ up to the amount of government bonds carried over from the previous period $B_{t-1}$ discounted by $R_{t}^{m}$. Hence, privately issued debt is not eligible in open market operations, which accords to common practice of central banks (like the BoE or the US-Fed in normal times) to restrict the set of eligible securities mainly to short-term government bonds (see e.g. Meulendyke, 1998). Accordingly, we assume that only government bonds can be used as collateral for money in open market operations, such that household $i$ faces the following open market constraint

$$
I_{i, t} \leq B_{i, t-1} / R_{t}^{m}
$$

In principle, the central bank can also withdraw money from the private sector $\left(I_{i, t}<\right.$ $0)$. Here, however, we focus on the empirically relevant case where the central bank creates a "structural deficiency" when it supplies money outright $\left(M^{H}\right),{ }^{14}$ by choosing a particular relation between money supplied under repurchase agreements and under outright sales/purchases. This strategy leads to a sufficiently large fraction of money that will be supplied under repurchase agreements to guarantee $I_{i, t} \geq 0$ in equilibrium (see below).

Households are further assumed to rely on cash for transactions in the goods market. Given that they can first trade with the central bank in open market operations, the cashin-advance constraint differs from Svensson's (1985) cash-in-advance constraint by $I_{i, t}$

$$
P_{t} c_{i, t} \leq I_{i, t}+M_{i, t-1}^{H}
$$

\footnotetext{
${ }^{14}$ This strategy has for example been applied by the US-Federal Reserve: "To most effectively influence the level of reserve balances, the Federal Reserve has created what is called a 'structural deficiency'. That is, it has created permanent additions to the supply of reserve balances that are somewhat less than the total need. Then on a seasonal and daily basis, the Desk is in a position to add balances temporarily to get to the desired level." (see "Fedpoint: Open Market Operations", http://www.newyorkfed.org/aboutthefed/fedpoint/fed32.html).
} 
In the asset market, the household receives pay-off from maturing assets, can buy bonds from the government, and can trade all assets with other households. It can further borrow and lend using a full set of nominally state contingent claims. Dividing the period $t$ price of one unit of nominal wealth in a particular state of period $t+1$ by the period $t$ probability of that state gives the stochastic discount factor $q_{t, t+1}$. The period $t$ price of a payoff $D_{j t}$ in period $t+1$ is then given by $E_{t}\left[q_{t, t+1} D_{j t}\right]$. Substituting out the stock of bonds and money held before the asset market opens, $\widetilde{B}_{i, t}$ and $\widetilde{M}_{i, t}$, in (4), the asset market constraint of household $i$ reads can be written as

$$
\begin{aligned}
& \left(B_{i, t} / R_{t}\right)+E_{t}\left[q_{t, t+1} D_{i, t}\right]+M_{i, t}^{H}+\left(R_{t}^{m}-1\right) I_{i, t} \\
& \leq B_{i, t-1}+D_{i, t-1}+M_{i, t-1}^{H}+P_{t} w_{t} n_{i, t}-P_{t} c_{i, t}+P_{t} \delta_{i, t}+P_{t} \tau_{t},
\end{aligned}
$$

where household $i^{\prime} s$ borrowing is restricted by the following no-Ponzi game condition

$$
\lim _{s \rightarrow \infty} E_{t} q_{t, t+s} D_{i, t+s} \geq 0
$$

as well as by $M_{i, t}^{H} \geq 0$ and $B_{i, t} \geq 0$. The term $\left(R_{t}^{m}-1\right) I_{i, t}$ in (8) measures the costs of money acquired in open market operations: the households receive new cash $I_{i, t}$ in exchange for $R_{t}^{m} I_{i, t}$ bonds.

Maximizing the objective (5) subject to the open market constraint (6), the goods market constraint (7), the asset market constraints (8) and (9), for given initial values $M_{i,-1}, B_{i,-1}$, and $D_{i,-1}$ leads to the following first order conditions for working time $n_{i, t}$, consumption $c_{i, t}$, additional money $I_{i, t}$, as well as holdings of contingent claims, government bonds and money:

$$
\begin{aligned}
-u_{i, n t} / w_{t} & =\lambda_{i, t}, \\
u_{i, c t} & =\lambda_{i, t}+\psi_{i, t}, \\
R_{t}^{m}\left(\lambda_{i, t}+\eta_{i, t}\right) & =\lambda_{i, t}+\psi_{i, t}, \\
\frac{\beta}{\pi_{t+1}} \frac{\lambda_{i, t+1}}{\lambda_{i, t}} & =q_{t, t+1}, \\
\beta E_{t}\left[\left(\lambda_{i, t+1}+\eta_{i, t+1}\right) \pi_{t+1}^{-1}\right] & =\lambda_{i, t} / R_{t}, \\
\beta E_{t}\left[\left(\lambda_{i, t+1}+\psi_{i, t+1}\right) \pi_{t+1}^{-1}\right] & =\lambda_{i, t},
\end{aligned}
$$

where $\lambda_{i, t}$ and $\psi_{i, t}$ denote the multiplier on the asset and goods market constraint. The conditions (10) and (11) show that $\lambda_{i, t}>0$ and that a binding goods market constraint $\left(\psi_{i, t}>0\right)$ distorts the intratemporal consumption-leisure decision in a conventional way, $u_{i, c t}+u_{i, n t} / w_{t}=\psi_{i, t}$. Combining (10) and (11) with (15), discloses the standard inflation tax on consumption, which is implied by the cash-in-advance constraint (7):

$$
\beta E_{t}\left[u_{i, c t+1} / \pi_{t+1}\right]=-u_{i, n t} / w_{t} .
$$


Throughout, we will repeatedly refer to the rate of return on a nominally risk-free portfolio of claims that deliver one unit of currency in each state. This debt rate $R_{t}^{d}$ is given by $R_{t}^{d}=\left[E_{t} q_{t, t+1}\right]^{-1}$ and thus (see 13)

$$
1 / R_{t}^{d}=\beta E_{t}\left[\left(\lambda_{i, t+1} / \lambda_{i, t}\right) / \pi_{t+1}\right]
$$

The debt rate closely relates to the Euler rate in section 2. It can differ from the standard Euler rate (see 1) solely due to the cash-credit-good friction $\lambda_{i, t} \leq u_{i, c t}$ (see 11). To facilitate comparisons, we will report results for both rates, though the Euler rate has no meaningful role in the model.

The open market constraint (6) is associated with the multiplier $\eta_{i, t} \geq 0$, which measures the liquidity value of bonds. When the goods market constraint is binding: $\psi_{i, t}>0 \Leftrightarrow$ $u_{i, c t}+u_{i, n t} / w_{t}>0$ (see 10 and 11), the role of money as a means of payment is positively valued. Likewise, government bonds, as a substitute for money, can also be valued differently from non-eligible assets; for this, the price of money in terms of bonds $R^{m}$ has to be sufficiently low. Combining (10), (11), and (12), we obtain

$$
\eta_{i, t}=\frac{u_{i, n t}}{w_{t}}+\frac{u_{i, c t}}{R_{t}^{m}}
$$

The multiplier on the open market constraint $\eta_{i, t}$, tends to decline with the policy rate (see 18), since a higher policy rate reduces the amount of money for each unit of bonds supplied to the central bank. The bond pricing equation (14) shows that a rise in this multiplier tends to lower the interest rate on bonds. Hence, a positive liquidity value of bonds $\eta_{i, t}>0$ gives rise to a liquidity premium between the interest rate on bonds and the debt rate, $s_{t}=R_{t}^{d}-R_{t}>0$, as can be seen from (14) and (17), which can be combined to

$$
\frac{R_{t}^{d}}{R_{t}}=\frac{E_{t}\left[\left(\lambda_{i, t+1}+\eta_{i, t+1}\right) / \pi_{t+1}\right]}{E_{t}\left[\lambda_{i, t+1} / \pi_{t+1}\right]}
$$

The household's investment decisions further links the bond rate to the policy rate. It is willing to hold both assets, money and bonds, if the rate of return on bonds compensates for the costs of acquiring new money in the next period. This can be seen by combining (10), (12), (14), and (15) to

$$
1 / R_{t}=\frac{E_{t}\left[\left(1 / R_{t+1}^{m}\right)\left(u_{i, c t+1} / \pi_{t+1}\right)\right]}{E_{t}\left[\left(u_{i, c t+1} / \pi_{t+1}\right)\right]}
$$

implying that the interest rate on bonds equals the expected future policy rate up to first order. Finally, the transversality conditions for money, bonds, and private debt as well as the following complementary slackness conditions are satisfied in the household's optimum
i) $0 \leq b_{i, t-1} \pi_{t}^{-1} / R_{t}^{m}-i_{i, t}, \quad \eta_{i, t} \geq 0, \quad \eta_{i, t}\left(b_{i, t-1} \pi_{t}^{-1} / R_{t}^{m}-i_{i, t}\right)=0$,
ii) $\quad 0 \leq i_{i, t}+m_{i, t-1}^{H} \pi_{t}^{-1}-c_{i, t}, \quad \psi_{i, t} \geq 0, \quad \psi_{i, t}\left(i_{i, t}+m_{i, t-1}^{H} \pi_{t}^{-1}-c_{i, t}\right)=0$, 
where $m_{i, t}^{H}=M_{i, t}^{H} / P_{t}, b_{i, t}=B_{i, t} / P_{t}$, and $i_{i, t}=I_{i, t} / P_{t}$, and (8) and (9) hold with equality. Households are then willing to hold both types of money, i.e. money held under repurchase agreements $M_{i, t}^{R}$ and under outright sales/purchases $M_{i, t}^{H}$. Changes in the composition of money supplied to the private sector might affect the distribution of eligible securities between the private sector and the central bank.

In the following sections, we will particularly be interested in the case where the open market constraint (6) is binding, $\eta_{i, t}>0$. It should however be noted that this does not imply that fiscal policy (or total government debt) is decisive for the maximum amount of money supplied. A more elaborate set-up could for example also contain longer term government bonds that are accepted to a smaller extend by the Fed in exchange for money than shortterm government bonds (see e.g. Federal Reserve of New York, 2006). ${ }^{15}$ While we assume, for simplicity, that all one period government bonds are eligible, central banks in practice typically decide on the fraction of eligible securities that they actually accept in open market operations. In fact all main results derived in this paper will not be affected either if we add non-eligible government bonds with longer maturity or if we assume that only a fraction of government bonds are accepted in open market operations. ${ }^{16}$

Firms To facilitate a reasonable transmission of monetary shocks we allow for imperfectly flexible prices. We introduce price stickiness in a simple way following the New Keynesian literature. In particular, we assume that the final consumption good is an aggregate of differentiated goods produced by monopolistically competitive firms indexed with $j \in[0,1]$. The CES aggregator of differentiated goods is $y_{t}^{\frac{\epsilon-1}{\epsilon}}=\int_{0}^{1} y_{j t}^{\frac{\epsilon-1}{\epsilon}} d j$, with $\epsilon>1$, where $y_{t}$ is the number of units of the final good, $y_{j t}$ the amount produced by firm $j$, and $\epsilon$ the constant elasticity of substitution. Let $P_{j t}$ and $P_{t}$ denote the price of good $j$ set by firm $j$ and the price index for the final good. The demand for each differentiated good is $y_{j t}=\left(P_{j t} / P_{t}\right)^{-\epsilon} y_{t}$, with $P_{t}^{1-\epsilon}=\int_{0}^{1} P_{j t}^{1-\epsilon} d j$. A firm $j$ produces good $y_{j}$ employing the technology: $y_{j t}=a_{t} n_{j t}^{\alpha}$, where $\alpha \in(0,1), a$ is a stochastic productivity level satisfying $a_{t}=a_{t-1}^{\rho_{a}} \exp \varepsilon_{a, t}, \rho_{a} \geq 0$, and $\varepsilon_{a, t}$ is i.i.d. normally distributed with $E_{t-1} \varepsilon_{a, t}=0$ a constant standard deviation st.dev. $\left(\varepsilon_{a}\right) \geq 0$. Hence, labor demand satisfies

$$
w_{t}=m c_{j t} \alpha y_{j t} / n_{j t},
$$

where $m c_{j t}$ denotes real marginal costs.

We consider a nominal rigidity in form of staggered price setting as in Yun (1995). Each period firms may reset their prices with the probability $1-\phi$ independently of the time

\footnotetext{
${ }^{15}$ For example, if we include non-eligible two-period government bonds they would exhibit the period $t$ price $1 / R_{t}^{l}=\left(1 / R_{t}^{d}\right) E_{t}\left(1 / R_{t+1}^{d}\right)$, which can be associated with a "term premium" compared to one-period (eligible) government bonds $1 / R_{t}^{l} \leq\left(1 / R_{t}\right) E_{t}\left(1 / R_{t+1}\right)$.

${ }^{16}$ In particular, by extending the type of eligible securities or by reducing the fraction of accepted government bonds, the central bank can freely chose its long-run inflation target (see section 3.5 for a discussion).
} 
elapsed since the last price setting. The fraction $\phi \in[0,1)$ of firms is assumed to adjust their prices with the steady state inflation rate $\pi$, where $\pi_{t}=P_{t} / P_{t-1}$, such that $P_{j t}=\pi P_{H, j t-1}$. In each period a measure $1-\phi$ of randomly selected firms sets new prices $\widetilde{P}_{j t}$ in order to maximize the expected sum of discounted future dividends $P_{t} \delta_{j t}=\left(P_{j t}-P_{t} m c_{t}\right) y_{j t}$ : $\max _{\widetilde{P}_{j t}} E_{t} \sum_{s=0}^{\infty} \phi^{s} q_{t, t+s}\left(\widetilde{P}_{j t} y_{j t+s}-P_{t+s} m c_{t+s} y_{j t+s}\right)$, s.t. $y_{j t+s}=\widetilde{P}_{j t}{ }^{-\epsilon} P_{t+s}^{\epsilon} y_{t+s}$. For $\phi>0$, the first order condition is given by

$$
\widetilde{P}_{j t}=\frac{\epsilon}{\epsilon-1} \frac{E_{t} \sum_{s=0}^{\infty} \phi^{s}\left[q_{t, t+s} y_{t+s} P_{t+s}^{\epsilon+1} m c_{t+s}\right]}{E_{t} \sum_{s=0}^{\infty} \phi^{s}\left[q_{t, t+s} y_{t+s} P_{t+s}^{\epsilon}\right]} .
$$

Aggregate output is $y_{t}=\left(P_{t}^{*} / P_{t}\right)^{\epsilon} n_{t}^{\alpha}$, where $\left(P_{t}^{*}\right)^{-\epsilon}=\int_{0}^{1} P_{j t}^{-\epsilon} d j$ and thus $\left(P_{t}^{*}\right)^{-\epsilon}=\phi\left(P_{t-1}^{*}\right)^{-\epsilon}+$ $(1-\phi) \widetilde{P}_{t}^{-\epsilon}$. Under flexible prices $\phi=0$, real marginal costs are given by $m c_{t}=\frac{\varepsilon-1}{\varepsilon}$.

\subsection{Public sector}

The public sector consists of a government and a central bank. The government issues oneperiod bonds $B^{T}$, which are held by households and by the central bank. For simplicity, we assume that the supply of government bonds is exogenously determined and is issued at a constant growth rate $\Gamma$ satisfying

$$
\Gamma>\beta: B_{t}^{T}=\Gamma B_{t-1}^{T}
$$

It should be noted we do not aim at modelling the evolution of total public debt by (23). Of course, public debt also consists of government bonds with longer maturity that might grow with a rate different from $\Gamma$, which will not be modelled here to keep the exposition simple. Hence, (23) can be viewed as a supply of a particular asset that the central bank declares eligible rather than a characterization of total public debt. In order to avoid any further effects of fiscal policy we assume that the government can raise or transfer revenues in a non-distortionary way, $P_{t} \tau_{t}$. As long as bonds with longer maturities are not eligible (which roughly accords to common central bank practice), we can therefore neglect them without any consequences for the analysis of monetary policy effects.

Accounting for the transfers $P_{t} \tau_{t}^{m}$ from the central bank, the simplified government budget is balanced by

$$
\left(B_{t}^{T} / R_{t}\right)+P_{t} \tau_{t}^{m}=B_{t-1}^{T}+P_{t} \tau_{t}
$$

The central bank supplies money in exchange for government bonds in open market operations in form of outright sales/purchases $M_{t}^{H}$ and repurchase agreements $M_{t}^{R}$. Before the money market opens, the central bank's stock of government bonds equals $B_{t-1}^{c}$ and the stock of outstanding money equals $M_{t-1}^{H}$. It then receives an amount of bonds $\Delta B_{t}^{c}$ in exchange for money $I_{t}$, and after repurchase agreements are settled its holdings of bonds reduces by $B_{t}^{R}$ and the amount of outstanding money by $M_{t}^{R}=B_{t}^{R}$. Before the asset market opens, where 
the central bank can invest in government bonds $B_{t}^{c}$, it holds an amount of bonds equal to $\widetilde{B}_{t}^{c}=\Delta B_{t}^{c}+B_{t-1}^{c}-B_{t}^{R}$. Its budget constraint is given by

$$
\left(B_{t}^{c} / R_{t}\right)+P_{t} \tau_{t}^{m}=\Delta B_{t}^{c}+B_{t-1}^{c}-B_{t}^{R}+M_{t}^{H}-M_{t-1}^{H}-\left(I_{t}-M_{t}^{R}\right) .
$$

In accordance with the operational practice of central banks we assume that it rolls over its maturing assets (see e.g. Meulendyke, 1998, ch.7). Thus, we assume that the central bank also enters the asset market at the end of each period, and reinvests in bonds to the amount that equals its current stock of maturing debt $B_{t}^{c}=\widetilde{B}_{t}^{c}$. Further using $B_{t}^{R}=M_{t}^{R}$ and $\Delta B_{t}^{c}=R_{t}^{m} I_{t}$, the budget constraint can be simplified to $\left(B_{t}^{c} / R_{t}\right)-B_{t-1}^{c}=M_{t}^{H}-M_{t-1}^{H}+$ $\left(R_{t}^{m}-1\right) I_{t}-P_{t} \tau_{t}^{m}$.

Following common practice (see Meulendyke, 1998), we assume that the central bank transfers interest earnings from asset holdings to the government:

$$
P_{t} \tau_{t}^{m}=B_{t}^{c}\left(1-1 / R_{t}\right)
$$

Note that these transfers will not be negative in equilibrium, such that the central bank will never rely on funds from the government. ${ }^{17}$ Accordingly, its bond holdings will evolve according to

$$
B_{t}^{c}-B_{t-1}^{c}=R_{t}^{m} I_{t}-\left(I_{t}-M_{t}^{H}+M_{t-1}^{H}\right) .
$$

Thus the central bank receives more bonds from households, when money supply or the policy rate is high (see 25). The term in brackets on the RHS of (25) accounts for money supplied under repos, which reduces the latter effect.

Regarding the implementation of monetary policy, we assume that the central bank conducts monetary policy by using simple instrument rules. The central bank sets the policy rate $R_{t}^{m}$ contingent on its own lags, current inflation, and current real activity, which is measured as in Justiniano and Primiceri (2008). To assess the monetary transmission mechanism, we further consider shocks to the following Taylor-rule-type interest rate reaction function

$$
R_{t}^{m}=\left(R_{t-1}^{m}\right)^{\rho_{R}}\left(R^{m}\right)^{1-\rho_{R}}\left(\pi_{t} / \pi\right)^{\rho_{\pi}\left(1-\rho_{R}\right)}\left(\left(y_{t} / a_{t}\right) /(y / a)\right)^{\rho_{y}\left(1-\rho_{R}\right)} \exp \varepsilon_{R, t} .
$$

where $\rho_{\pi} \geq 0, \rho_{y} \geq 0, \rho_{R} \geq 0$ and $\varepsilon_{R, t}$ is normally i.i.d. with $E_{t-1} \varepsilon_{R, t}=0$ and a constant standard deviation st.dev. $\left(\varepsilon_{R}\right) \geq 0$. The long-run policy rate, $R^{m}>1$, and the target inflation rate, $\pi>\beta$, can be chosen by the central bank. Note that the interest rate rule encompasses the case of exogenous interest rate policies, $\rho_{\pi}=\rho_{y}=0$, which we found to be consistent with local equilibrium determinacy in cases where the open market constraint (6)

\footnotetext{
${ }^{17}$ This is different in standard models, where central bank transfers seigniorage (defined as the change in the monetary base) to the government in each period. A discussion of government transfers and central bank independence can be found in Sims (2003).
} 
is binding. A short discussion of this property can be found in section 5.1.

In contrast to standard models, where repurchase agreements are not considered, the central bank has an additional role: it can decide on whether money is traded in form of outright sales/purchases or in form of repurchase agreements. For simplicity, we assume that it chooses a constant ratio of money supply under both types of open market operations $\Omega$ :

$$
M_{t}^{R}=\Omega \cdot M_{t}^{H},
$$

or $M_{t}^{R}=M_{t} \frac{\Omega}{1+\Omega}$, where $M_{t}$ is the total money supply, $M_{t}=M_{t}^{H}+M_{t}^{R}$. We assume that $\Omega>0$ to account for the fact that the Trading Desk of the Federal Reserve Bank of New York "structures its outright holdings to maintain a need to routinely add to balances by arranging repurchase agreements" (see Fed New York, 2006). This "structural deficiency", i.e., the choice of an appropriate relation between money supplied under repurchase agreements and under outright sales/purchases, allows the Fed to keep a tight control over the federal funds rate in a flexible way.

\subsection{Rational expectations equilibrium}

In equilibrium, there will be no arbitrage opportunities and markets clear, $n_{t}=\int_{0}^{1} n_{j t} d j=$ $\int_{0}^{1} n_{i t} d i$ and $y_{t}=\int_{0}^{1} y_{j t} d j=\int_{0}^{1} c_{i t} d i=c_{t}$. Households will not behave differently and aggregate asset holdings satisfy $\forall t \geq 0: \int_{0}^{1} D_{i, t} d i=0, \int_{0}^{1} M_{i, t}^{H} d i=\int_{0}^{1} \widetilde{M}_{i, t} d i=M_{t}^{H}$, $\int_{0}^{1} M_{i, t}^{R} d i=M_{t}^{R}, \int_{0}^{1} B_{i, t} d i=B_{t}, \int_{0}^{1} B_{i, t}^{c} d i=B_{t}^{c}, \int_{0}^{1} I_{i, t} d i=I_{t}=M_{t}^{H}-M_{t-1}^{H}+M_{t}^{R}$, and $B_{t}^{T}=B_{t}+B_{t}^{c}$.

Since the government bond is the single eligible security, its distribution between the central bank and the private sector will matter. Given that the government issues bonds according to a constant growth rate $\Gamma$, household bond holdings change according to $B_{t}-$ $B_{t-1}=(\Gamma-1) B_{t-1}^{T}-B_{t}^{c}+B_{t-1}^{c}$. Further using (25), the evolution of bonds held by households satisfies

$$
B_{t}-B_{t-1}=(\Gamma-1) B_{t-1}^{T}-R_{t}^{m}\left(M_{t}^{H}-M_{t-1}^{H}+M_{t}^{R}\right)+M_{t}^{R} .
$$

Thus, private sector holdings of bonds tend to decrease with a higher price of money $R^{m}$ and to increase with $\Gamma$. For a given injection $I_{t}$ households further loose less bonds when the fraction of money held under repurchase agreements increases.

Throughout, we will focus on the case where the central bank sets its instrument such that the goods market constraint $(7)$ is strictly binding $\left(\psi_{t}>0\right)$. In the long-run, this is ensured by a sufficiently large inflation target, $\pi>\beta$ (see section 3.5). A rational expectations equilibrium can then be defined as follows:

A rational expectations equilibrium is a set of sequences $\left\{c_{t}, n_{t}, y_{t}, w_{t}, m_{t}, b_{t}, b_{t}^{T}, R_{t}^{m}\right.$, $\left.R_{t}^{d}, R_{t}, P_{t}\right\}_{t=0}^{\infty}$ satisfying the firms' first order conditions and the production technology, the households' first order conditions (10)-(15) and the transversality condition, the binding 
goods market constraint $P_{t} c_{t}=M_{t}^{H}+M_{t}^{R}$, the open market constraint

$$
\frac{b_{t-1}}{R_{t}^{m} \pi_{t}} \geq m_{t}^{R}+m_{t}^{H}-m_{t-1}^{H} \pi_{t}^{-1}
$$

and $b_{t}-b_{t-1} \pi_{t}^{-1}=(\Gamma-1) b_{t-1}^{T} \pi_{t}^{-1}-R_{t}^{m}\left(m_{t}^{H}-m_{t-1}^{H} \pi_{t}^{-1}\right)-\left(R_{t}^{m}-1\right) m_{t}^{R}$, for $\Gamma=b_{t}^{T} \pi_{t} / b_{t-1}^{T}$, for a monetary policy satisfying (26), given $\left\{a_{t}\right\}_{t=0}^{\infty}$ and initial values $M_{-1} \geq 0, B_{-1}>0$, and $P_{-1}>0$.

Note that under a non-binding open market constraint, $b_{t-1} / \pi_{t}>R_{t}^{m}\left(m_{t}^{R}+m_{t}^{H}-m_{t-1}^{H} \pi_{t}^{-1}\right)$, the evolution of government bonds will neither affect the equilibrium allocation nor the associated price system. If however the open market constraint is binding, $b_{t-1} /\left(R_{t}^{m} \pi_{t}\right)=m_{t}^{R}+$ $m_{t}^{H}-m_{t-1}^{H} \pi_{t}^{-1}$, household bond holdings matter and (27) reduces to $B_{t}=(\Gamma-1) B_{t-1}^{T}+M_{t}^{R}$.

\subsection{Steady state}

In the following analysis, the two cases of a binding and a non-binding open market constraint (6) will be treated separately, which facilitates analyzing the mechanisms that are responsible for the main results. ${ }^{18}$ Throughout the analysis, we are particularly interested in the case where the open market constraint is binding. The central bank can conduct monetary policy in a way that ensures the rate of return on government bonds to be lower on average than the rate of return on private debt in equilibrium. This case is consistent with the empirical observation that the policy rate has almost always been below the implied Euler rate (see Figure 1). Households then tend to economize on bond holdings, i.e. they will not hold more government bonds than necessary for their money market trades. If however both returns are identical, households can borrow and invest in government bonds without costs such that the open market constraint will not be binding. ${ }^{19}$

In order to analyze interest rates and monetary policy for the two regimes in a separate way, we examine steady states with a binding and a non-binding open market constraint. We then assume that monetary policy is conducted in a way that implements one particular steady state and that aggregate shocks are sufficiently small, so that we can analyze the dynamic properties of the economy in the neighborhood of this steady state. A steady state value of an endogenous variable $x_{t}$ will not carry a time index, $x$.

To examine the two cases, we use (19) which leads to the following steady state condition for the multiplier on the open market constraint $\eta \geq 0$

$$
\eta / \lambda=\left(R^{d}-R\right) / R
$$

\footnotetext{
${ }^{18}$ The set of equilibrium conditions for both cases can be found in the appendix 8.2. To simplify the analysis, we disregard the long-run dispersion of prices at inflation rates exceeding one.

${ }^{19}$ Likewise, if the central bank simply declares both assets as eligible for open market operations, the private sector can freely create any amount of private debt that can be used in exchange for money, such that the private sector never runs out of eligible securities.
} 
Thus a strictly positive spread between the debt rate $R^{d}$ and the bond rate $R$ implies the multiplier on the open market constraint to be strictly positive $\eta>0$. The open market constraint is then binding in the steady state.

Before examining the differences between both steady states, we look their at common properties. Throughout the paper, we assume that the central bank successfully implements its inflation target $\pi$ in the long-run. The steady state Euler rate is, as usual, determined by (17), $R^{d}=\pi / \beta$. Combining (15) and (17) gives $R_{t}^{d} E_{t}\left[\lambda_{i, t+1} / \pi_{t+1}\right]=E_{t}\left[\left(\lambda_{i, t+1}+\psi_{i, t+1}\right) / \pi_{t+1}\right]$, which in steady state demands the multiplier on the cash-in-advance constraint (7) to satisfy

$$
\psi / \lambda=R^{d}-1
$$

Together with $R^{d}=\pi / \beta$, condition (29) implies that the cash-in-advance constraint is binding in the steady state, if the inflation target exceeds $\beta, \pi>\beta$, which will be assumed throughout the analysis. Further using (16), (21), and $c=n^{\alpha}$, shows that steady state consumption is given by

$$
c^{\sigma+1 / \alpha-1}=\frac{\beta}{\pi} \frac{\varepsilon-1}{\varepsilon} \frac{\alpha}{\gamma},
$$

while real balances satisfy $m=c, m^{H}+m^{R}=m$, and $m^{R}=\Omega m^{H}$. Thus, for a fixed inflation target $\pi>\beta$, the steady state values $R^{d}, c, y=c, n=y^{1 / \alpha}, m, m^{h}$ and $m^{R}$ are independent of $\eta$, i.e. do not depend on the tightness of the money market constraint. Nevertheless, monetary policy is non-neutral in the long-run due to the inflation tax on consumption (see 30) originating in the cash-credit-good distortion induced by the cash-in-advance constraint (7). The following proposition summarizes these properties.

Proposition 1 If the central bank sets the inflation target and the steady state policy rate such that $\pi>\beta$ and $R^{m}<\pi / \beta$, the goods market constraint and the open market constraint are binding in the steady state. The equilibrium allocation in the steady state is then identical to the case where the open market constraint is not binding and independent of the policy rate.

The open market constraint only matters for the steady state values for the bond rate $R$ and for the real value of government bonds $b$.

i.) If the central bank sets the average policy rate $R^{m}$ equal to the debt rate $R^{d}$ in a steady state, $R^{m}=\pi / \beta$, the interest rate on government bonds $R=R^{m}$ (see 20) also equals $R^{d}$. By (28), the multiplier on the open market constraint will then be equal to zero $\eta=0$ and the steady state is characterized by $R=R^{d}=R^{m}$. Since the open market constraint is not binding, there are infinitely many values for real bonds consistent with a long-run equilibrium.

ii.) If however the central bank chooses an average policy rate $R^{m}$ that is strictly smaller than $R^{d}$, which requires $R^{m}<\pi / \beta$, the open market constraint is binding and the 
steady state is characterized by $R=R^{m}$,

$$
\frac{b}{R^{m} \pi}=m^{H}\left(1-\pi^{-1}\right)+m^{R},
$$

and $b=(\Gamma-1) b^{T} \pi^{-1}+m^{R}$. Combining the latter with (31) and $m^{R}=\Omega m^{H}$, shows that $b^{T}$ will be strictly positive in a non-deflationary steady state. For a realistic inflation target $\pi \geq 1$, which will be considered throughout the analysis, (23) implies that the inflation target equals the growth rate of short-term government bonds, $\Gamma=\pi$.

As mentioned before, we do not interpret the equality $\Gamma=\pi$ (in case $i i$.) as a restriction for the central bank's inflation target to depend on public debt: first, $B^{T}$ just measures the supply of short-term government bonds, while total public debt, of course, also contains longterm bonds that are disregarded in our model for simplicity. And second, the central bank is in principle free to adjust the set of eligible securities, and can thereby chose an inflation target that differs from $\Gamma$. If, for example, the central bank chooses a smaller inflation target $\pi<\Gamma$, it can simply accept smaller fractions of government bonds in open market operations. Otherwise, for $\pi>\Gamma$, it might also declare other assets (or a fraction of them) as eligible, which grow with a rate that exceeds $\Gamma .^{20}$ In any case, the central bank can actually decide on the maximum amount of money that can be traded in open market operations by deciding on the set of eligible securities. Though this is not explicitly modelled in this paper, we can easily account for these arguments by allowing for a richer asset structure, which will nevertheless leave the main results unchanged.

\section{Interest rates and spreads}

In this section, we examine the relation between the three interest rates, i.e., the policy rate $R_{t}^{m}$, the bond rate $R_{t}$, and the debt rate $R_{t}^{d}$. The bond rate $R_{t}$ and the policy rate $R_{t}^{m}$ are closely related to each other as can be seen from (20). The spread between these two rates, which can be interpreted as a risk premium, will be examined below. Before, we examine the spread between the debt rate $R_{t}^{d}$ and the bond rate $R_{t}$, which is a liquidity premium. We will show that both the spread $R_{t}^{d}-R_{t}$ and the debt rate $R_{t}^{d}$ itself decrease when the central bank raises the policy rate $R^{m}$, which is consistent with the empirical evidence provided in section 2 .

For the analysis in this section we will use a simplified version of the model, to facilitate the derivation of analytical results. Throughout this section, we assume that production is linear $(\alpha=1)$, the production sector is perfectly competitive $(\epsilon \rightarrow \infty)$, and that prices are

\footnotetext{
${ }^{20}$ In light of the decline in the amount of outstanding US-treasury debt, the latter case was in fact viewed as a relevant issue in 2001. See Board of Governors (2001) for a comprehensive discussion on alternative assets that were considered for open market purchases. This issue has regained interest in the current financial crises, where the Fed and other central banks relaxed their asset acquisition policy.
} 
perfectly flexible $(\phi=0)$. We further assume in this section that money is only supplied via repurchase agreements $M_{t}=M_{t}^{R}(\Omega \rightarrow \infty)$ and that the supply of government bonds is constant $(\Gamma=1)$.

\subsection{The liquidity premium}

Households are willing to hold government bonds even if the bond rate is lower than the debt rate, since bonds exhibit an additional liquidity value (see 19). Due to lower interest earnings, households will economize on bond holdings such that the open market constraint (6) is binding. This property has already been discussed in the previous section, where we have shown that the central bank can implement a long-run equilibrium with a binding money market constraint if the policy rate $R^{m}$ is set at a value lower than $R^{d}=\pi / \beta$ (see proposition 1). In the neighborhood of this steady state, the spread between the debt rate and the bonds rate will not be constant over time and will in particular be affected by the monetary policy stance, since the liquidity value of bonds will depend on the money market conditions.

To facilitate an exact analysis of the liquidity premium, we restrict our attention to the case of an exogenous interest rate policy $\rho_{\pi}=\rho_{y}=0$. Since the current bond rate is affected by tomorrow's policy rate rather than today's policy rate (see 20), we further assume that the policy rate sequence exhibits inertia $\rho_{R}>0 .{ }^{21} \mathrm{~A}$ rise in the policy rate $R_{t}^{m}$ then has two immediate effects. It reduces nominal consumption for a given stock of household bond holdings $B_{t-1}$ (see 6 and 7 ). It further leads to lower end-of-period nominal bond holdings $B_{t}$ (see 27, which for $M_{t}=M_{t}^{R}$ and $\Gamma=1$ reduces to $\left.B_{t}=B_{t-1} / R_{t}^{m}\right)$. Thus, both effects tend to reduce inflation. Since the policy rate is raised in an inertial way, inflation is also expected to be lower in the subsequent period, such that households demand a lower debt rate $R_{t}^{d}$ (see 17$)$.

These results can easily be derived for the simplified version when utility is logarithmic in consumption $\sigma=1 .^{22}$ They are summarized in the following proposition.

Proposition 2 Consider the simplified version, where $\sigma=1$ and the policy rate satisfies $\rho_{\pi}=\rho_{y}=0$ and $R^{m}<1 / \beta$. Then, in the neighborhood of the steady state the debt rate $R_{t}^{d}$ and the ratio $R_{t}^{d} / R_{t}$ decrease with $i$.) the current level of the policy rate if $\rho_{R}>0$ and ii.) with the variance of policy rate innovations $\varepsilon_{R, t}$.

Proof. See appendix 8.3.

The spread $R_{t}^{d}-R_{t}$, i.e., the liquidity premium, originates in the ability of bonds to be convertible into means of payments in open market operations before the goods market opens.

\footnotetext{
${ }^{21}$ Under perfectly flexible prices both rates, $R^{d}$ and $R$, will be constant if $\rho_{R}=0$. This will not be the case for the calibrated version of the model considered in section 5 .

${ }^{22}$ As mentioned above, the simplified version is further characterized by $\alpha=1, \epsilon \rightarrow \infty, \phi=0, \Omega \rightarrow \infty$, and $\Gamma=1$.
} 
If the costs of exchanging bonds against money $R_{t}^{m}$ increases, the liquidity value of bonds and thus the liquidity premium decline. Similarly, when the variance of the policy rate increases, the liquidity value of bonds becomes more uncertain and the liquidity premium is reduced. Put differently, when the costs associated with the liquidation of bonds get more risky, the compensating interest rate $R$ increases. This effect resembles the concept of a liquidity risk premium (see Acharya and Pedersen, 2005).

According to the standard Fischer (expected inflation) effect, the debt rate $R^{d}$ falls in response to an increase in the policy rate, since inflation is expected be to lower than average inflation rate in the subsequent period. It should be noted that this inflation response is further responsible for an increase in consumption, since the inflation tax on cash goods is then lowered (see 16). This counterfactual consumption response will disappear when prices are considered to be imperfectly flexible (see section 5 ).

\subsection{The risk premium}

As discussed in the previous section, the interest rates on bonds and debt only differ when the open market constraint is binding. In contrast, there can be a spread between the policy rate and the bond rate, regardless whether the open market constraint is binding or not. This can be seen from (20), which be rewritten as

$$
1 / R_{t}=E_{t}\left(1 / R_{t+1}^{m}\right)+\frac{\operatorname{cov}_{t}\left[\left(1 / R_{t+1}^{m}\right),\left(u_{c t+1} / \pi_{t+1}\right)\right]}{E_{t}\left[u_{c t+1} / \pi_{t+1}\right]} .
$$

Households are willing to hold both, money and bonds, if the rate of return on bonds compensates for the costs of converting bonds into money in next period's open market operations. Up to first order, the current bond price $1 / R_{t}$, which is determined in the asset market in period $t$, equals the expected future money-price of bonds in open market operations $E_{t}\left(1 / R_{t+1}^{m}\right)$. For the case of a binding open market constraint, the price of a government bond $1 / R_{t}$ can be shown to be smaller than $E_{t}\left(1 / R_{t+1}^{m}\right)$. The reason is that the covariance on the RHS of (32) is negative, i.e., the real policy rate $R_{t+1}^{m}$ is positively related to the mar-

ginal utility of consumption divided by the inflation rate, $u_{c t+1} / \pi_{t+1}$. The spread between the bond rate and the expected policy rate then tends to be positive and increases with the measure of relative risk aversion $\sigma$. Hence, this spread is a risk premium on the nominal rate of return on bonds compared to the expected policy rate: a risk-averse agent who considers investing in bonds in the asset market will ask for a price $1 / R_{t}$ that is lower than the expected money-price of bonds in next period's open market market, if a lower policy rate (and thus a higher pay-off from bonds) is expected to be associated with higher consumption and inflation.

To establish this result, we again apply the simplified version of the model $(\alpha=\Gamma=1$, $\phi=0, \epsilon \rightarrow \infty$, and $\Omega \rightarrow \infty)$. We now allow for varying degrees of relative risk aversion, 
$\sigma>1$, and we focus on white noise technology shocks, $\rho_{a}=0$, as the only source of aggregate uncertainty, such that $\varepsilon_{R, t}=0$, while the policy rate will endogenously be adjusted according to $\rho_{\pi}>0$ and $\rho_{R}=\rho_{y}=0$. The following proposition summarizes the main results.

Proposition 3 Consider the simplified version, where $\sigma>1$ and $\rho_{a}=0$, while the policy rate satisfies $\rho_{\pi}>0, \rho_{R}=\rho_{y}=0, \varepsilon_{R, t}=0$ and $R^{m}<1 / \beta$. Then, in the neighborhood of the steady state the current price of government bonds is smaller than the expected future money-price of bonds $1 / R_{t}<E_{t}\left(1 / R_{t+1}^{m}\right)$. The average bond rate $R_{t}$ further increases with the households' relative risk aversion and with the variance of productivity shocks.

Proof. See appendix 8.4.

The covariance term in (32) is strictly negative under a binding open market constraint, since a higher policy rate tends to reduce current consumption times inflation $b_{t-1} / R_{t}^{m}=c_{t} \pi_{t}$. Then, the bond rate tends to exceed the policy rate and further increases for a given policy rate, if aggregate risk, st.dev. $\left(\varepsilon_{a}\right)$, or the degree of relative risk aversion $\sigma$ increases. In both cases households are only willing to hold bonds at a higher interest rate $R$.

\section{$5 \quad$ Numerical analysis}

In this section we apply a numerical analysis of a calibrated model. We first describe how we calibrate the model, then we re-examine the behavior of interest rates, and finally we explain the transmission of monetary policy shocks.

\subsection{Parameter values}

To allow for responses of consumption and inflation that are more realistic than before, we consider imperfectly flexible prices, $\phi>0$. For most of the model's parameter we apply standard values for quarterly data (see table A1 in appendix 8.5). In particular, we set the inverse of the elasticity of intertemporal substitution $\sigma$, the labor income share $\alpha$, the fraction of non-optimally price adjusting firms $\phi$, and the elasticity of substitution $\epsilon$ equal to $\sigma=2$, $\alpha=2 / 3, \phi=0.8$, and $\epsilon=6$, while $\gamma$ is adjusted to get a steady state value of working time equal to $n=1 / 3$. The parameters for the stochastic productivity process are taken from Schmitt-Grohe and Uribe (2007) and are given by $\rho_{a}=0.856$ and st.dev. $\left(e_{a}\right)=0.0064$. The policy rate is set according to an inertial Taylor rule (see 26), where we used parameter values estimated by Justiniano and Primiceri (2008) for 1984-2004: $\rho_{R}=0.84, \rho_{\pi}=2.37$, $\rho_{y}=0.02$, and st.dev. $\left(e_{R}\right)=0.0015$.

Throughout the analysis, we restrict our attention to locally determined equilibria. When the open market constraint is not binding, our model reduces to an almost standard New Keynesian model and local equilibrium determinacy requires interest rate policy to satisfy the Taylor-principle (like the inertial Taylor-rule). If however the open market constraint is binding, we find that local equilibrium determinacy applies regardless whether interest rate 
policy satisfies the Taylor principle or is exogenous. We will then also apply an exogenous policy $\left(\rho_{\pi, y}=0\right.$ and $\left.\rho_{R}=0.84\right)$ to isolate effects of exogenous interest rate changes from effects due to endogenous interest rate adjustments. The reason why local equilibrium determinacy does not rely on an active policy in this case, is that a bounded supply of eligible securities (23) serves as a nominal anchor similar to the stock of money under a money growth policy. ${ }^{23}$

To match the average interest rate presented in section 2, we apply a target quarterly policy rate equal to $R^{m}=1.065^{1 / 4}=1.0159$, a (quarterly) debt rate equal to $R^{d}=1.114^{1 / 4}=$ 1.0274 , leading to a spread $s=0.0115$, and a inflation rate equal to $\pi=1.044^{1 / 4}=1.0108$. The steady state values for $R^{d}$ and $\pi$ are linked by the Euler equation, which in the steady state reads $R^{d}=\pi \beta^{-1}\left(1+\gamma_{c}\right)^{\sigma}$, where $\gamma_{c}$ is the steady state consumption growth rate. While real consumption growth rate $\gamma_{c}$ is strictly positive in the data, it is neglected in the model, for simplicity. We therefore set the discount factor $\beta$ equal to $\beta=0.984$, which is smaller than values usually applied in the business cycle literature, to compensate for a positive steady state consumption growth rate (see also King et al., 2002). It turns out that the choice of $\beta$ does not significantly affect the quantitative results. Finally, we chose 1.5 for the policy parameter $\Omega$ to match the observed ratio between total reserves and reserves supplied under repurchase agreements. This ratio was almost constant in the 2000 s before the $\operatorname{crisis}^{24}$.

\subsection{Interest rate behavior}

In this section we again take a look at the interest rates, which have already been analyzed qualitatively in section 4 . Here, we relate the results of the simulated model to the analytical results presented in proposition 2 and 3 and to the empirical evidence presented in section 2. To account for the effects of second moments on asset prices, we apply a second order approximation at the deterministic steady state (see Schmitt-Grohé and Uribe, 2004). ${ }^{25}$

The main properties of the debt rate and the liquidity premium are summarized in proposition 2. Consistent with the empirical evidence provided in section 2, it implies that both are negatively correlated with the policy rate. To prove this claim we neglected technology shocks. Here, we examine the magnitude of the correlations for the calibrated model, where technology shocks are also considered. Table 2 presents the correlation between the debt rate and the policy rate as well as the correlations between the spread $E_{0} s_{t}=E_{0}\left(R_{t}^{d}-R_{t}\right)$ and the policy rate. It further contains the corresponding values for the Euler rate $R_{t}^{E u l e r}$ and the

\footnotetext{
${ }^{23}$ This property of our model is in fact closely related to the determinacy property of the cash-in-advance model with sticky prices derived in Adao et al. (2003), who examine the case where both, the nominal interest rate and the supply of money are controlled by the central bank at the same time. A local determinacy analysis for our model is available upon request from the authors.

${ }^{24}$ See Federal Reserve Bank of New York, Domestic Open Market Operations, various issues, and FRED database.

${ }^{25}$ For the computation we used dynare.
} 
spread $E_{0} s_{t}^{\text {Euler }}=E_{0}\left(R_{t}^{\text {Euler }}-R_{t}\right)$, where $R^{\text {Euler }}$ is the rate implied by a standard Euler equation, $\beta E_{t}\left[u_{c, t+1} /\left(u_{c, t} \pi_{t+1}\right)\right]=1 / R_{t}^{E u l e r}$; the latter has no meaningful role in our model and is only computed to facilitate comparisons. ${ }^{26}$

The correlations are highly negative when only interest rate shocks are considered (second column), while they are less pronounced when only technology shocks are considered (third column). When we consider both types of shocks, the correlations take intermediate values (see last column). Overall, the correlations between the spreads and the policy rate are larger in absolute terms than the correlations between the debt rate (or Euler rate) and the policy rate. In sum, the correlations presented in table 2 come close to the empirical correlations presented in table 1 in section 2 .

Table 2 Unconditional correlations of HP-filtered series $(\lambda=1600)$

\begin{tabular}{lccc}
\hline \hline & Interest rate shocks & Technology shocks & Int. rate \& techn. shocks \\
\hline $\operatorname{corr}\left(s_{t}, R_{t}^{m}\right)$ & -0.99 & -0.82 & -0.94 \\
$\operatorname{corr}\left(s_{t}^{\text {Euler }}, R_{t}^{m}\right)$ & -0.99 & -0.85 & -0.94 \\
$\operatorname{corr}\left(R_{t}^{d}, R_{t}^{m}\right)$ & -0.93 & -0.63 & -0.76 \\
$\operatorname{corr}\left(R_{t}^{\text {Euler }}, R_{t}^{m}\right)$ & -0.97 & -0.77 & -0.85 \\
\hline \hline
\end{tabular}

With the parameter values discussed above, the liquidity premium $s_{t}$ (measured in term of the debt rate) exhibits a mean value equal to 490 basis points in terms of annualized rates. In accordance with the second claim in proposition 2 it declines with the variance of policy rate innovations $\varepsilon_{R, t}$. Increasing the standard deviation of policy rate innovations st.dev $\left(e_{R}\right)$ from 0.0015 to 0.003 and to 0.006 indeed reduces the mean spread from 490 to 489 and to 487 , respectively. This effect is more pronounced (488 and 483) when the policy rate is assumed to follow an exogenous process.

As summarized in proposition 3, the risk premium, i.e. the spread between the bond rate and the policy rate, has been shown to increase with the standard deviation of the productivity shock st.dev. $\left(\varepsilon_{a}\right)$ and the relative risk aversion $\sigma$. These effects are also found in the calibrated version, while the size of the risk premium is extremely small (0.064 basis points for the benchmark parametrization and 0.095 basis points for $\sigma=5$ ). We expect that this spread can be increased if other sources of risk, e.g. shocks related to financial intermediation (see Christiano et al., 2007), are also considered in the model, which is beyond the scope of this paper.

\footnotetext{
${ }^{26}$ Here we followed the exposition in proposition 1 and computed spreads for the bond rate. Corresponding spreads for the policy rate are almost identical.
} 


\subsection{Monetary transmission}

In this section we analyze the monetary transmission mechanism. Consider a positive innovation to the policy rate satisfying (26). Figure 3 presents the impulse responses of interest rates and macroeconomic aggregates for the case where the policy rate is set exogenously $\left(\rho_{\pi}=\rho_{y}=0\right.$ and $\rho_{R}=0$, black solid line) and for the case where it follows the Taylor type feedback rule $\left(\rho_{R}=0.84, \rho_{\pi}=2.37, \rho_{y}=0.02\right.$, red marked line). An increase of the policy rate by 15 basis points (or 60 basis points in terms of annualized rates) from its steady state value leads to a rise in the bond rate on impact by less than 15 basis points, since the current bond rate tends to increase with the future expected policy rate (see 32). In contrast, the debt rate $R_{t}^{d}$ falls on impact and is closely followed by the Euler rate $R^{\text {Euler }}$. The spread between the debt rate and the bond rate decreases. Both responses are consistent with the claims made in proposition 1 . On impact the spread falls by up to $17 \%$ of its steady state value.

Regarding the consumption response, figure 3 further shows that consumption (which equals output, $y_{t}=c_{t}$ ) declines in a hump-shaped way, which is qualitatively consistent with VAR evidence (see Christiano et al., 1999). The hump-shaped decline of consumption implies a fall in its growth rate. This pattern, together with the decline in inflation, is consistent with a fall in the Euler rate and the debt rate. Notably, hump-shaped impulse responses can usually not be observed in response to policy rate shocks in simple sticky price models. In these models consumption typically falls on impact and returns monotonically to its steady state value, which is consistent with an increase in the consumption growth rate (see also figure 5 below).

Hump-shaped responses can of course also be generated by sticky price models that contain further features like habits or additional frictions (see Bernanke et al., 1999 or Christiano et al., 2005). Here, the shape of the consumption response is mainly driven by households' holdings of eligible securities. To get an intuition for this, consider an inertial rise in the policy rate. Due to the higher relative price of money, households can get less cash in the same period such that consumption and inflation fall on impact. While the fall in inflation tends to raise the real value of total government bonds, the share of bonds held by the central bank increases with higher policy rates (see 25). Thus, a monetary tightening does not only lead to contractionary effects on impact, but tends to shift the mass of bonds towards the central bank. With diminishing eligible securities, households can also get less money in the subsequent periods, such that the initial contraction in consumption will even be enhanced. Then, the inflation effects starts dominating the interest rate effect and real bond holdings of households recover. Thus, the distribution of bond holdings affects the transmission of monetary policy shocks, which relies on the assumption that the central bank does not transfer its wealth to the household at the end of each period. 

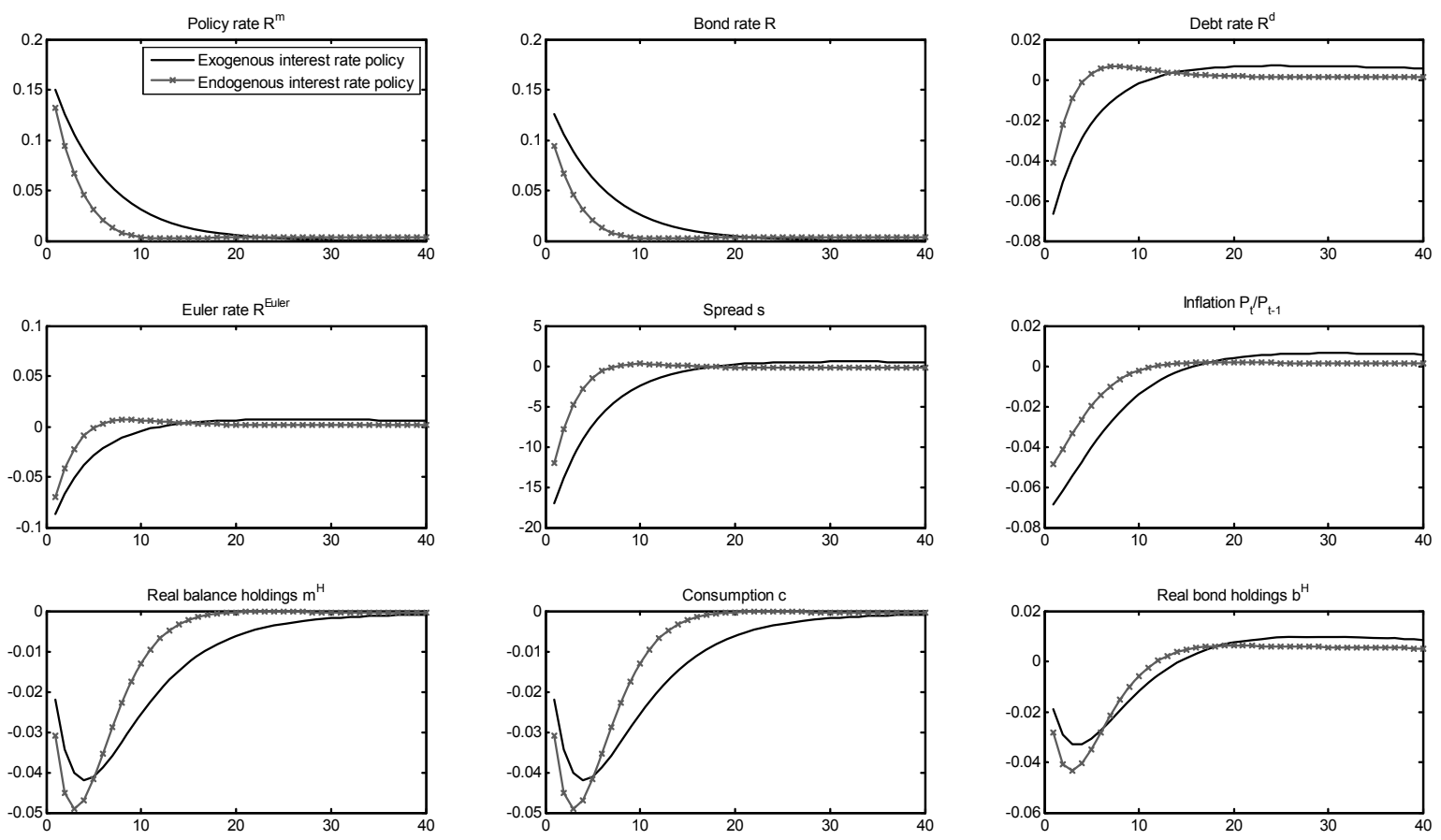

Figure 3: Responses (in \% dev. from st.st.) to a policy rate shock for a binding money market constraint

To illustrate this difference, we also consider the counterfactual case where the central bank transfers back interest earnings and all its financial wealth at the end of each period, such that all government bonds are held by households, $B_{t}=B_{t}^{T}$. The black solid line in figure 4 shows the impulse responses for this case (the red marked lines are the same as in figure 3). Consumption does not respond in a hump-shaped pattern and the debt rate actually increases after an rise in the policy rate.

Figure 5 further shows impulse responses to the same policy rate shock for a version of the model where the money market constraint is not binding. Given that the stock of government bonds is now irrelevant and the bond rate equals the debt rate, the responses of the latter, of the spread $s_{t}$, and of real bonds are not presented. The policy rate is set according to the Taylor rule, since determinacy now requires the Taylor-principle, like in standard New Keynesian models. We show responses for our benchmark value of the subjective discount factor $\beta=0.984$. A line representing a commonly applied value, like $\beta=$ 0.99 , would be almost indistinguishable from the lines in figure 5. Three main observations should be noted: first, the current debt rate follows the (expected future) policy rate, which is inconsistent with the empirical evidence provided in section 2. Second, the output response does not exhibit a hump shape, like in standard models where the distribution of asset holdings is irrelevant. Third, the effects of the same policy shock on inflation and on output 

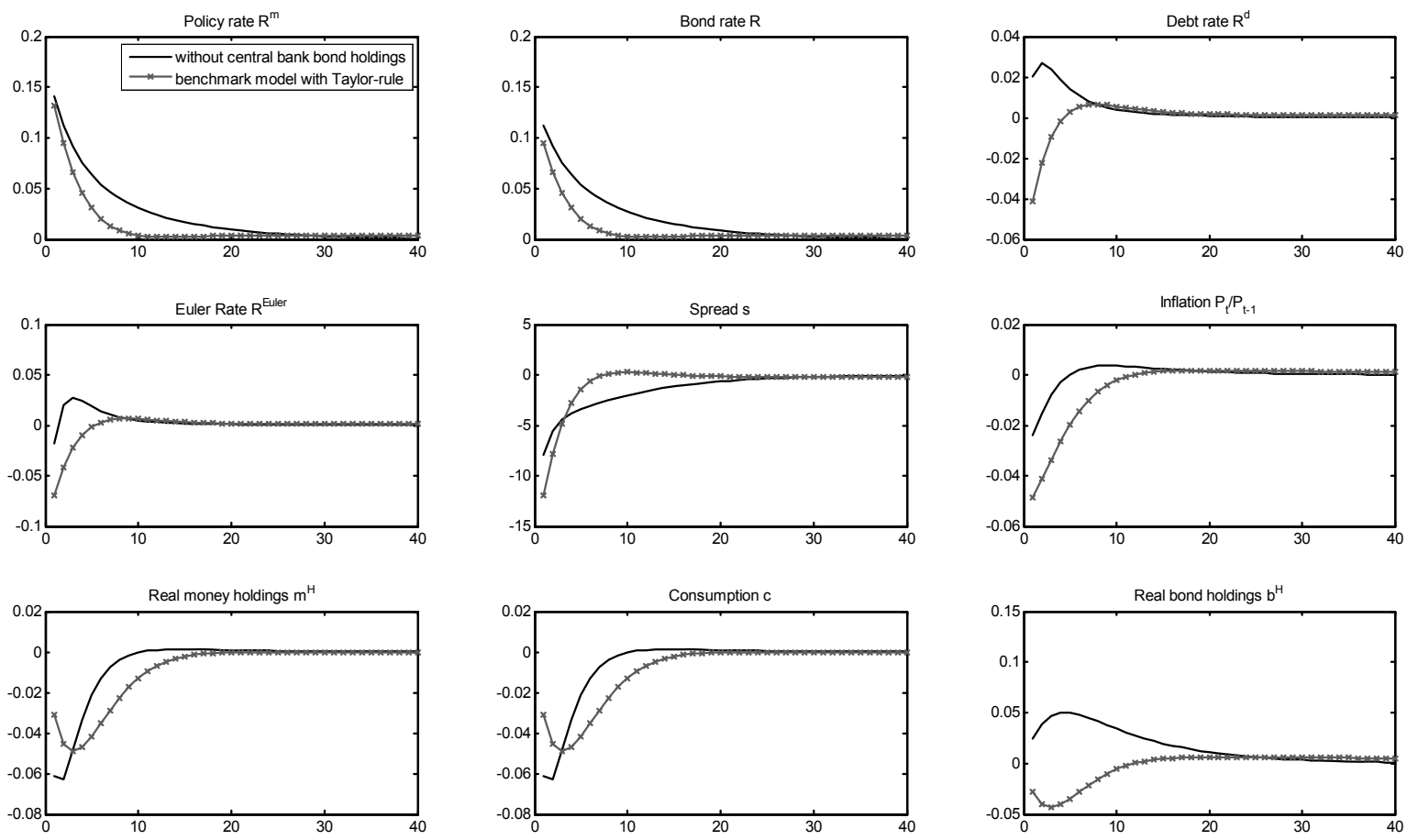

Figure 4: Responses (in \% dev. from st.st.) to an interest rate shock with conventional central bank transfers

are much more pronounced than for a binding open market constraint. The maximum output contraction is 60-times larger and the inflation contraction is 30-times than in the case where the open market constraint is binding. ${ }^{27}$

The reason why monetary policy effects are less pronounced in the case of a binding open market constraint is that a higher policy rate predominantly impacts on the level of real consumption due to the constraints in the money market and in the goods market. In contrast, when the open market constraint is not binding, a higher (real) policy rate immediately affects the growth rate of consumption via the consumption Euler equation. Put differently, when the open market constraint is binding, part of an increase in the policy rate reflects a decrease in liquidity premium (see 14) such that expected consumption growth and inflation is less affected than in a standard model. Compared to impulse responses of VARs (see e.g. Christiano et al., 2005), the response of consumption in response to a policy rate shock is about four times smaller in our model with a binding open market constraint (see figure 3). We expect that this gap can be closed when the model is augmented by endogenous investments and additional nominal or real rigidities.

\footnotetext{
${ }^{27}$ It should be noted that the output effect is more pronounced in our model than in a standard New Keynesian model, which neglects transaction frictions. Without the cash-credit good friction the impact output response would be reduced by more than $20 \%$.
} 

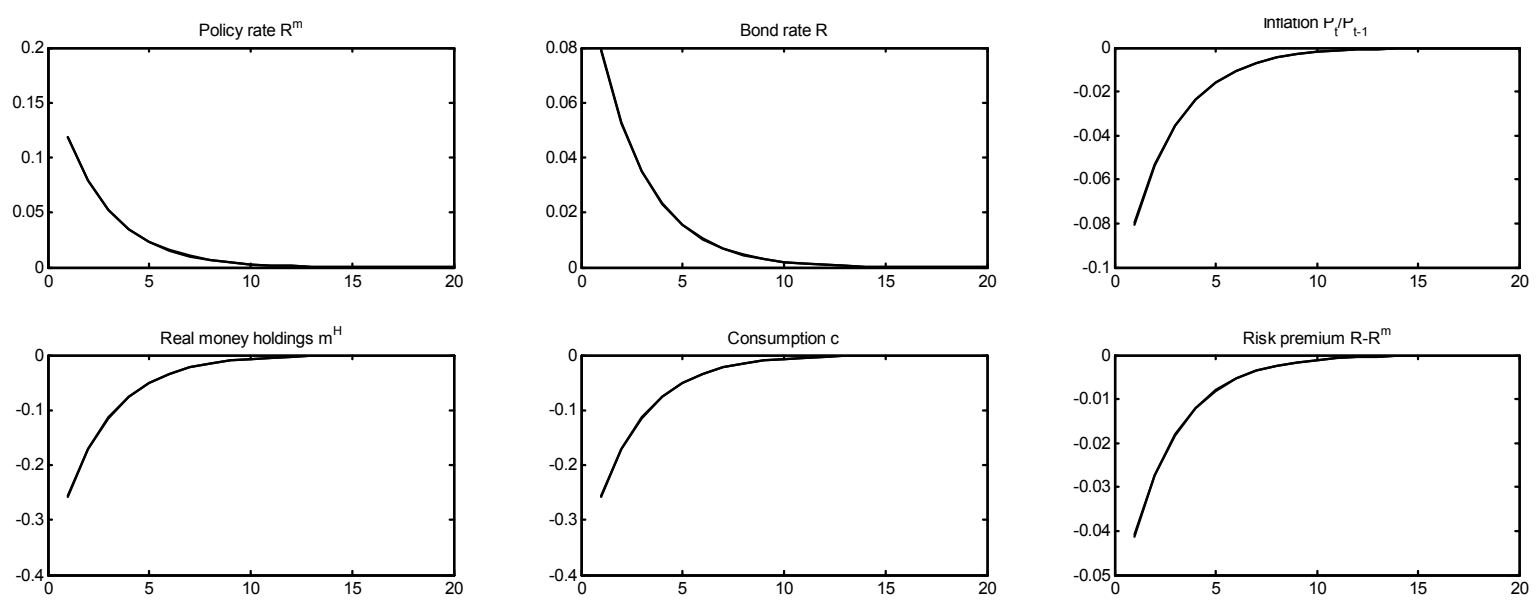

Figure 5: Responses (in \% dev. from st.st.) to an interest rate shock for a non-binding money market constraint

Finally, note that for a smaller fraction of repo money compared to money supplied outright, $\Omega=M_{t}^{R} / M_{t}^{H}$, the impact of an interest rate shock under a binding open market constraint, in particular, the responses of the macroeconomic aggregates, are less pronounced. The impulse responses to interest rate shocks for a $50 \%$ smaller value of $\Omega$ are shown in figure 6 . The responses show that the size of interest rate shock effects depends on the way the central bank conducts open market operations. The impact of a higher policy rate on consumption is less pronounced (i.e. the maximum contraction is reduced by $1 / 3$ ) for a smaller share of money supplied under repos. Hence, by creating a larger "structural deficiency" with respect to the outright supply of money, the central bank can increase the effectiveness of its actions.

\section{Conclusion}

In this paper we developed a macroeconomic framework where monetary policy implementation is modelled in a way that accounts for three fact that are typically neglected in standard macroeconomic models. First, the asset market is separated from the open market operations where the central bank supplies money in exchange for assets. Second, not all default-riskfree assets are eligible in open market operations, which gives rise to a liquidity premium on eligible assets, i.e. T-bills, compared to privately issued debt. Third, the central bank just transfers interest earnings from holding interest bearing assets, leading to a non-degenerate distribution of eligible assets.

We show that considering these three facts can help explaining the relation between policy rates, consumption growth, and the risk free interest rate that is difficult to account for in standard models. The existence of a liquidity premium in an arbitrage free equilibrium contributes to the solution of the risk free rate puzzle. The dynamics of the liquidity premium, 

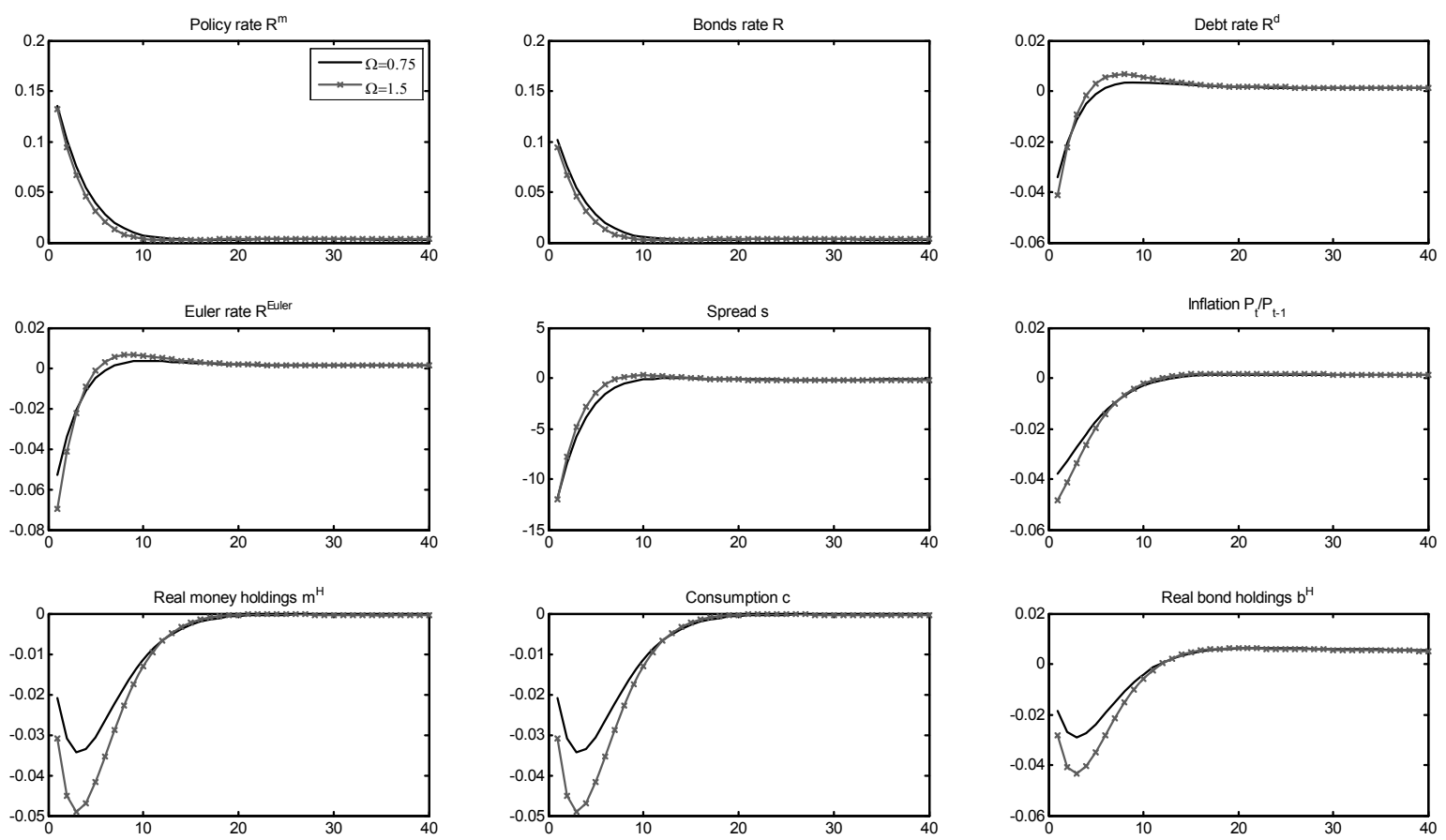

Figure 6: Responses (in \% dev. from st.st.) to an interest rate shock for $\Omega=0.75$ (black line) and $\Omega=1.5$ (red marked line)

in particular in response to policy rate changes, can further account for the systematic movements in the spread between the Euler rate and the policy rate, as recently documented by Canzoneri et al. (2007) and Atkeson and Kehoe (2008). Moreover, the effect of monetary policy on the distribution of scarce eligible assets, which gives rise to hump-shaped consumption responses to policy shocks, can even explain the negative relation between the Euler rate and the policy rate at business cycle frequencies. Finally, the analysis shows that the responses of consumption and inflation to a monetary policy shock are substantially dampened compared to the case where it is counterfactually assumed that the policy rate equals the Euler rate.

Besides the exercises conducted in this paper, this framework can serve as a useful instrument for the analysis of time varying liquidity effects and especially of unconventional policy options at the zero lower bound (ZLB) on interest rates. 


\section{References}

Acharya V.V. and L.H. Pedersen, 2005, Asset pricing with liquidity risk, Journal of Financial Economics 77, 375-410.

Adao, B., I. Correia, and P. Teles, 2003, Gaps and Triangles, Review of Economic Studies, 70, 699-713.

Aiyagari, R.S. and M. Gertler, 1991, Asset returns with transactions costs and uninsured individual risk, Journal of Monetary Economics 27, 311-331.

Atkeson, A., and P.J. Kehoe, 2009, On the Need for a New Approach to Analyzing Monetary Policy, NBER Macroeconomics Annual, forthcoming.

Bansal, R., and W.J. Coleman II., 1996, A Monetary Explanation of the Equity Premium, Term Premium, and Risk-Free Rate Puzzle, Journal of Political Economy 104 , $1135-1171$.

Bernanke, B., M. Gertler and S. Gilchrist, 1999, The Financial Accelerator in a Quantitative Business Cycle Framework, in: M. Woodford and J.B. Taylor (eds.), Handbook of Macroeconomics, North-Holland, Amsterdam, 1341-1393.

Canzoneri M.B., R. E. Cumby, and B.T. Diba, 2007, Euler equations and money market interest rates: A challenge for monetary policy models, Journal of Monetary Economics $54,1863-1881$.

Canzoneri M.B., R. E. Cumby, B.T. Diba, and D. Lopez-Salido, 2008, Monetary Aggregates and Liquidity in a Neo-Wicksellian Framework, Journal of Money, Credit and Banking 40, 1667-1698.

Christiano, J.L., M. Eichenbaum, and C.L. Evans, 2005, Nominal Rigidities and the Dynamic Effects of a Shock to Monetary Policy, Journal of Political Economy 113, 1-45.

Christiano L., R. Motto and M. Rostagno, 2007, Financial Factors in Business Cycles, Northwestern University.

Goodfriend, M., and B.T. McCallum, 2007, Banking and Interest Rates in Monetary Policy Analysis: A quantitative exploration, Journal of Monetary Economics 54, 14801507.

Eisfeldt, A.L., 2007, Smoothing with Liquid and Illiquid Assets, Journal of Monetary Economics 54, 1572-1586.

Federal Reserve Bank of New York, 2006, Domestic Open Market Operations during 2006. 
Fuhrer, J. C., 2000, Habit Formation in Consumption and its Implications for MonetaryPolicy Models, American Economic Review 90, 367-390.

Justiniano, A. and G. E. Primiceri, 2008, The Time-Varying Volatility of Macroeconomic Fluctuations, American Economic Review 98, 604-41.

King, R.G., Plosser, C.I. and S.T. Rebelo, 2002, Production, Growth and Business Cycles: Technical Appendix, Computational Economics 20, 87-116.

Kiyotaki, N. and Moore, J., 2008, Liquidity, Business Cycles, and Monetary Policy, Princeton University.

Holmstrom, B. and J. Tirole, 2001, LAPM: A Liquidity-Based Asset Pricing Model, Journal of Finance 56, 1837-1867.

Lacker, J.E., 1997, Clearing, Settlement and Monetary Policy, Journal of Monetary Economics 40, 347-381.

Lagos, R., 2006, Asset Prices and Liquidity in an Exchange Economy, Federal Reserve Bank of Minneapolis, Research Department Staff Report 373.

Meulendyke, A.M., 1998, U.S. Monetary Policy and Financial Markets, Federal Reserve Bank of New York, New York.

Schmitt-Grohé, S., and M. Uribe, 2004, Solving Dynamic General Equilibrium Models Using a Second-Order Approximation to the Policy Function, Journal of Economics Dynamic and Control 28, 755-775.

Schmitt-Grohé, S., and M. Uribe, 2007, Optimal, Simple, and Implementable Monetary and Fiscal Rules, Journal of Monetary Economics 54, 1702-1725.

Sims, C. A., 2005, Limits to Inflation Targeting, in: The Inflation-Targeting Debate, B.S. Bernanke and M. Woodford, eds., NBER Studies in Business Cycles 32. 283-310.

Smets, F., and R. Wouters, 2007, Shocks and Frictions in U.S. Business Cycles: A Bayesian DSGE approach. American Economic Review 97, 586-606.

Svensson, L.E.O., 1985, Money and Asset Prices in a Cash-in-advance Model, Journal of Political Economy 93, 919-944.

Weil, P., 1989, The Equity Premium Puzzle and the Risk-free rate Puzzle, Journal of Monetary Economics 24, 401-421.

Woodford, M., 2003, Interest and Prices: Foundations of a Theory of Monetary Policy, Princeton: Princeton University Press. 
Yun, T., 1996, Nominal Price Rigidity, Money Supply Endogeneity, and Business Cycles, Journal of Monetary Economics 37, 345-370. 


\section{Appendix}

\subsection{Computation of the Euler rate}

In section 2, the empirical Euler interest rate $r^{d}$ implied by our model has been computed as $\frac{1}{1+r_{t}^{d}}=\beta \exp \left[\begin{array}{c}-\sigma\left(E_{t} \log c_{t+1}-\log c_{t}\right)-E_{t} \log \pi_{t+1}-E_{t} r_{t+1}^{m}+r_{t}^{m}+\frac{\sigma^{2}}{2} \operatorname{var}_{t} \log c_{t+1}+\frac{1}{2} v a r_{t} \log \pi_{t+1} \\ +\frac{1}{2} v a r_{t} r_{t+1}^{m}+\sigma \operatorname{cov}_{t}\left(\log c_{t+1}, \log \pi_{t+1}\right)+\sigma \operatorname{cov}_{t}\left(\log c_{t+1}, r_{t+1}^{m}\right)+\operatorname{cov}_{t}\left(\log \pi_{t+1}, r_{t+1}^{m}\right)\end{array}\right]$.

\subsection{Equilibrium conditions}

A rational expectations equilibrium for a binding money market constraint and a binding goods market constraint is a set of sequences $\left\{c_{t}, n_{t}, y_{t}, w_{t}, m_{t}^{R}, m_{t}^{H}, m c_{t}, R_{t}^{m}, R_{t}^{d}, R_{t}, b_{t}, \pi_{t}\right\}_{t=0}^{\infty}$ satisfying

$$
\begin{aligned}
m_{t}^{R}+m_{t}^{H} & =c_{t}, \\
m_{t}^{R} & =\Omega m_{t}^{H}, \\
\frac{b_{t-1}}{R_{t}^{m} \pi_{t}} & =m_{t}^{R}+m_{t}^{H}-m_{t-1}^{H} \pi_{t}^{-1}, \\
\beta E_{t} \frac{u_{c t+1}}{\pi_{t+1}} & =\frac{-u_{n t}}{w_{t}}, \\
w_{t} & =m c_{t} \alpha y_{t} / n_{t}, \\
1 / \beta & =R_{t}^{d} E_{t} \frac{-u_{n t+1}\left(n_{t+1}\right) / w_{t+1}}{-u_{n t}\left(n_{t}\right) / w_{t}} \pi_{t+1}^{-1}, \\
R_{t} & =\frac{E_{t} u_{c t+1}\left(c_{t+1}\right) \pi_{t+1}^{-1}}{E_{t}\left(R_{t+1}^{m}\right)^{-1} u_{c t+1}\left(c_{t}\right) \pi_{t+1}^{-1}}, \\
y_{t} & =a_{t} n_{t}^{\alpha},
\end{aligned}
$$

and either $m c_{t}=\frac{\varepsilon-1}{\varepsilon}$ and $y_{t}=c_{t}$ for flexible prices or $(22)$ with $\widetilde{P}_{j t}=\widetilde{P}_{t}$, and $P_{t}^{1-\epsilon}=$ $\phi\left(P_{t-1}\right)^{1-\epsilon}+(1-\phi) \widetilde{P}_{t}^{1-\epsilon}, y_{t}=\left(P_{t}^{*} / P_{t}\right)^{\epsilon} n_{t}^{\alpha}$, where $\left(P_{t}^{*}\right)^{-\epsilon}=\phi\left(P_{t-1}^{*}\right)^{-\epsilon}+(1-\phi) \widetilde{P}_{t}^{-\epsilon}$ for sticky prices, and a sequence for household's bond holdings satisfying

$$
\begin{aligned}
b_{t}-b_{t-1} \pi_{t}^{-1} & =(\Gamma-1) b_{t-1}^{T} \pi_{t}^{-1}-R_{t}^{m}\left(m_{t}^{H}-m_{t-1}^{H} \pi_{t}^{-1}\right)-\left(R_{t}^{m}-1\right) m_{t}^{R}, \\
b_{t}^{T} & =\Gamma b_{t-1}^{T} \pi_{t}^{-1},
\end{aligned}
$$

the households' transversality conditions for money, bonds, and private debt, for a monetary policy (26), productivity levels $\left\{a_{t}\right\}_{t=0}^{\infty}$ and initial asset endowments. (For convenience, we neglect higher order terms of the aggregate supply constraint $\log \left(\pi_{t} / \pi\right)=\beta E_{t} \log \left(\pi_{t+1} / \pi\right)+$ $\chi \log \left(m c_{t} / m c\right)$, where $\chi=(1-\phi)(1-\beta \phi) / \phi$. For a detailed analysis of aggregate supply under sticky prices, see, e.g., the working paper version of Schmitt-Grohé and Uribe, 2007).

If the money market constraint is not binding, the sequence of bonds is irrelevant and the 
model can be reduced to a set of equilibrium sequences for $\left\{c_{t}, n_{t}, y_{t}, w_{t}, m_{t}, m c_{t}, R_{t}^{m}, R_{t}, \pi_{t}\right\}_{t=0}^{\infty}$ given by (37)-(40) $m_{t}=c_{t}, u_{c t}=R_{t}^{m} \frac{-u_{n t}}{w_{t}}$ and either $m c_{t}=\frac{\varepsilon-1}{\varepsilon}$ for flexible prices or $\log \left(\pi_{t} / \pi\right)=\beta E_{t} \log \left(\pi_{t+1} / \pi\right)+\chi \log \left(m c_{t} / m c\right)$ for sticky prices, the tvc's, and $\left\{a_{t}\right\}_{t=0}^{\infty}$, for a monetary policy $(26)$ and initial values.

\subsection{Proof of proposition 2}

Applying the parameter restrictions $\phi=\rho_{\pi}=\rho_{y}=0, \Gamma=\alpha=\sigma=1, \rho>0$, and $\Omega=\epsilon \rightarrow \infty$, the set of equilibrium conditions given in 8.2 for a binding open market constraint can be reduced to

$$
\begin{aligned}
m_{t}^{R} & =c_{t}, \quad \frac{b_{t-1}}{R_{t}^{m} \pi_{t}}=m_{t}^{R}, \quad \beta E_{t} \frac{c_{t+1}^{-1}}{\pi_{t+1}}=\frac{\gamma}{w_{t}} \\
w_{t} & =a_{t}, \quad y_{t}=a_{t} n_{t}, \quad y_{t}=c_{t}, \quad b_{t}-b_{t-1} \pi_{t}^{-1}=-\left(R_{t}^{m}-1\right) m_{t}^{R}, \\
1 / R_{t}^{d} & =\beta E_{t} \frac{a_{t+1}}{a_{t}} \pi_{t+1}^{-1}, \quad R_{t}=E_{t} R_{t+1}^{m},
\end{aligned}
$$

and a monetary policy. Eliminating consumption, the real wage rate, and output, it can further be reduced to a system in $b, \pi, R$, and $R^{d}$ satisfying (45)

$$
\beta E_{t} \frac{R_{t+1}^{m}}{b_{t}}=\frac{\gamma}{a_{t}}, \quad b_{t}=\frac{1}{R_{t}^{m} \pi_{t}} b_{t-1},
$$

and the policy rule $R_{t}^{m}=\left(R_{t-1}^{m}\right)^{\rho}\left(R^{m}\right)^{1-\rho} \exp \varepsilon_{t}^{\rho}$. Since this system is log-linear, and shocks are log-normally distributed, all variables are also log-normal. Thus, the two conditions in (46) can be written as

$$
\begin{aligned}
E_{t} \log R_{t+1}^{m}+(1 / 2) \operatorname{var}_{t}\left(\log R_{t+1}^{m}\right) & =\log b_{t}-\log a_{t}+\log \gamma / \log \beta \\
\log b_{t} & =-\log R_{t}^{m}-\log \pi_{t}+\log b_{t-1}
\end{aligned}
$$

where we used that $\log E_{t} R_{t+1}^{m}=E_{t} \log R_{t+1}^{m}+(1 / 2) \operatorname{var}_{t}\left(\log R_{t+1}^{m}\right)$ and $\operatorname{var}_{t}\left(x_{t+i}\right)=E_{t} \operatorname{var}\left(x_{t+i}\right)$. Using the logged policy rule $\log R_{t}^{m}=\rho \log R_{t-1}^{m}+(1-\rho) \log R^{m}+\varepsilon_{t}$ and defining $\kappa=$ $\log \gamma-\log \beta$, we get the following expressions for real bonds and inflation

$$
\begin{aligned}
& \log \pi_{t}=-(1+\rho) \log R_{t}^{m}+\log b_{t-1}-\log a_{t}-(1 / 2) \operatorname{var}_{t}\left(\log R_{t+1}^{m}\right)-(1-\rho) \log R^{m}+\kappa(47) \\
& \log b_{t}=\rho \log R_{t}^{m}+\log a_{t}+(1-\rho) \log R^{m}+(1 / 2) \operatorname{var}_{t}\left(\log R_{t+1}^{m}\right)-\kappa
\end{aligned}
$$

To assess the spread between the debt rate and the bonds rate, we apply the conditions in (45), which can be combined to

$$
R_{t} / R_{t}^{d}=\beta E_{t} R_{t+1}^{m} E_{t} \frac{a_{t}}{a_{t+1} \pi_{t+1}} .
$$


Taking $\operatorname{logs}$ and using $\log E_{t} R_{t+1}^{m}=E_{t} \log R_{t+1}^{m}+(1 / 2) \operatorname{var}_{t}\left(\log R_{t+1}^{m}\right)$, the ratio $R_{t}^{d} / R_{t}$ can be written as

$$
-\log \left(R_{t}^{d} / R_{t}\right)=\log a_{t}+\log \beta+E_{t} \log R_{t+1}^{m}+(1 / 2) \operatorname{var}_{t}\left(\log R_{t+1}^{m}\right)+\log E_{t}\left[a_{t+1}^{-1} \pi_{t+1}^{-1}\right] .
$$

Rewriting the last term $\log E_{t}\left[a_{t+1}^{-1} \pi_{t+1}^{-1}\right]$ by using $\log E_{t}\left[a_{t+1}^{-1} \pi_{t+1}^{-1}\right]=E_{t}\left(-\log a_{t+1}-\log \pi_{t+1}\right)+$ $(1 / 2) \operatorname{var}_{t}\left(-\log a_{t+1}-\log \pi_{t+1}\right)$ and $\operatorname{var}_{t}\left(-\log a_{t+1}-\log \pi_{t+1}\right)=\operatorname{var}_{t}\left(\log a_{t+1}\right)+\operatorname{var}_{t}\left(\log \pi_{t+1}\right)+$ $2 \operatorname{cov}_{t}\left(\log a_{t+1}, \log \pi_{t+1}\right)$, we get

$$
\begin{aligned}
-\log \left(R_{t}^{d} / R_{t}\right)= & \left(1-\rho_{a}\right) \log a_{t}+\log \beta+\rho \log R_{t}^{m}+(1-\rho) \log R^{m}-E_{t} \log \pi_{t+1} \\
& +(1 / 2) \operatorname{var}_{t}\left(\log R_{t+1}^{m}\right)+\operatorname{var}_{t}\left(\log a_{t+1}\right)+\operatorname{var}_{t}\left(\log \pi_{t+1}\right) \\
& +2 \operatorname{cov}_{t}\left(\log a_{t+1}, \log \pi_{t+1}\right)
\end{aligned}
$$

where we used $E_{t} \log a_{t+1}=\rho_{a} \log a_{t}$ and $E_{t} \log R_{t+1}^{m}=\rho \log R_{t}^{m}+(1-\rho) \log R^{m}$. Eliminating $E_{t} \log \pi_{t+1}$ with (47),

$$
\begin{aligned}
\log \left(R_{t}^{d} / R_{t}\right)= & -\log a_{t}-\rho(\rho+2) \log R_{t}^{m}+\log b_{t}-(1 / 2) E_{t}\left[\operatorname{var}_{t+1}\left(\log R_{t+2}^{m}\right)\right] \\
& -(1 / 2) \operatorname{var}_{t}\left(\log R_{t+1}^{m}\right)-\operatorname{var}_{t}\left(\log a_{t+1}\right)-\operatorname{var}_{t}\left(\log \pi_{t+1}\right) \\
& -2 \operatorname{cov}_{t}\left(\log a_{t+1}, \log \pi_{t+1}\right)-2(1-\rho) \log R^{m}+\kappa-\log \beta
\end{aligned}
$$

and further $\log b_{t}$ with (48), gives

$$
\begin{aligned}
\log \left(R_{t}^{d} / R_{t}\right)= & -\rho(1+\rho) \log R_{t}^{m}-(1 / 2) \operatorname{var}_{t}\left(\log R_{t+2}^{m}\right)-\log \beta-(1-\rho) \log R^{m} \\
& -\operatorname{var}_{t}\left(\log a_{t+1}\right)-\operatorname{var}_{t}\left(\log \pi_{t+1}\right)-2 \operatorname{cov}_{t}\left(\log a_{t+1}, \log \pi_{t+1}\right) .
\end{aligned}
$$

Using that (47) implies $\operatorname{var}_{t}\left(\log \pi_{t+1}\right)=(1+\rho)^{2} \operatorname{var}_{t}\left(\log R_{t+1}^{m}\right)+\operatorname{var}_{t}\left(\log a_{t+1}\right)$ as well as $\operatorname{cov}_{t}\left(\log a_{t+1}, \log \pi_{t+1}\right)=-\operatorname{var}_{t} \log a_{t+1}$, leads to

$$
\begin{aligned}
\log \left(R_{t}^{d} / R_{t}\right)= & -\rho(1+\rho) \log R_{t}^{m}-\log \beta-(1-\rho) \log R^{m} \\
& -(1 / 2) \operatorname{var}_{t}\left(\log R_{t+2}^{m}\right)-(1+\rho)^{2} \operatorname{var}_{t}\left(\log R_{t+1}^{m}\right) .
\end{aligned}
$$

Using $\operatorname{var}_{t}\left(\log R_{t+1}^{m}\right)=\operatorname{var}\left(\varepsilon^{\rho}\right)$ and $\operatorname{var}_{t}\left(\log R_{t+2}^{m}\right)=\left(1+\rho^{2}\right) \operatorname{var}\left(\varepsilon^{\rho}\right)$, we get $\log \left(R_{t}^{d} / R_{t}\right)=-\rho(1+\rho) \log R_{t}^{m}-\left((1 / 2)\left(1+\rho^{2}\right)+(1+\rho)^{2}\right) \operatorname{var}\left(\varepsilon^{\rho}\right)-\log \beta-(1-\rho) \log R^{m}$,

implying that the spread decreases with $R_{t}^{m}$ and $\operatorname{var}\left(\varepsilon^{\rho}\right)$, and requires $R^{m}<1 / \beta$. Further eliminating $\log R_{t}=\log E_{t} R_{t+1}^{m}$ using $\log E_{t} R_{t+1}^{m}=\rho \log R_{t}^{m}+(1-\rho) \log R^{m}+(1 / 2) \operatorname{var}_{t}\left(\log R_{t+1}^{m}\right)$, gives

$$
\log R_{t}^{d}=-\rho^{2} \ln R_{t}^{m}-\left((1 / 2) \rho^{2}+(1+\rho)^{2}\right) \operatorname{var}\left(\varepsilon^{\rho}\right)-\log \beta,
$$

which together with (49) establish the claims made in the proposition. 


\subsection{Proof of proposition 3}

We want to establish the claims made in proposition 3. For $\phi=\rho^{(a)}=\rho_{y}=0, \Gamma=\alpha=1$, $\sigma>1, \rho_{\pi}>0, \operatorname{var}_{\varepsilon^{\rho}}=0$, and $\Omega=\epsilon \rightarrow \infty$, the model with a binding ope market constraint can be reduced to a system in $b, c, \pi, R$, and $R^{d}$ satisfying (45),

$$
\frac{b_{t-1}}{R_{t}^{m} \pi_{t}}=c_{t}, \quad \beta E_{t} \frac{u_{c t+1}}{\pi_{t+1}}=\frac{\gamma}{a_{t}}, \quad b_{t}=\frac{1}{R_{t}^{m} \pi_{t}} b_{t-1}
$$

where $u_{c t}=c_{t}^{-\sigma}$, and a policy rule satisfying $R_{t}^{m}=R^{m}\left(\pi_{t} / \pi\right)^{\rho_{\pi}}$. Applying the latter and $u_{c t}=\left[b_{t-1} /\left(R_{t}^{m} \pi_{t}\right)\right]^{-\sigma}$, the covariance on the RHS of (32) can easily be shown to satisfy

$$
\operatorname{cov}_{t}\left[\left(1 / R_{t+1}^{m}\right),\left(u_{c t+1} / \pi_{t+1}\right)\right]=\left(R^{m} / \pi^{\rho_{\pi}}\right)^{\sigma-1} b_{t}^{-\sigma} \operatorname{cov}_{t}\left[\pi_{t+1}^{-\rho_{\pi}}, \pi_{t+1}^{\sigma \rho_{\pi}+\sigma-1}\right]<0,
$$

implying $1 / R_{t}<E_{t}\left(1 / R_{t+1}^{m}\right)$. In order to examine the impact of the relative risk aversion and of aggregate uncertainty on the bond rate, we derive the solutions for $b_{t}$ and $\pi_{t}$. Eliminating the policy rate in (46), we get two conditions for $b_{t}$ and $\pi_{t}$ :

$$
\begin{aligned}
\log b_{t} & =\rho_{\pi} E_{t} \log \pi_{t+1}+\log a_{t}+(1 / 2) \rho_{\pi}^{2} \operatorname{var}_{t}\left(\log \pi_{t+1}\right)+\kappa_{2}, \\
\left(1+\rho_{\pi}\right) \log \pi_{t} & =-\log b_{t}+\log b_{t-1}+\kappa_{3},
\end{aligned}
$$

where $\kappa_{2}=-\log \gamma+\log \beta+\log R^{m}-\rho_{\pi} \log \pi$ and $\kappa_{3}=-\log R^{m}+\rho_{\pi} \log \pi$. Since the model is log-linear, all variables will finally be log-normally distributed. We know that the solutions can be written in the following generic form

$$
\begin{aligned}
& \log \pi_{t}=\delta_{\pi b} \log b_{t-1}+\delta_{\pi a} \log a_{t}+\delta_{\pi v} \operatorname{var}_{t}\left(\log a_{t+1}\right)+\delta_{\pi}, \\
& \log b_{t}=\delta_{b b} \log b_{t-1}+\delta_{b a} \log a_{t}+\delta_{b v} \operatorname{var}_{t}\left(\log a_{t+1}\right)+\delta_{b},
\end{aligned}
$$

where the $\delta^{\prime} s$ are unknown constants. Inserting these solutions in (52) and (53), the unknown coefficients can easily be identified:

$$
\begin{aligned}
\log \pi_{t} & =\frac{1}{1+\rho_{\pi}} \log b_{t-1}-\log a_{t}-\frac{(1 / 2) \rho_{\pi}^{2}}{1+\rho_{\pi}} \operatorname{var}_{t}\left(\log a_{t+1}\right)+\kappa_{5} \\
\log b_{t} & =\left(1+\rho_{\pi}\right) \log a_{t}+(1 / 2) \rho_{\pi}^{2} \operatorname{var}_{t}\left(\log a_{t+1}\right)+\kappa_{4}
\end{aligned}
$$

where $\kappa_{4}=\exp \left(\log \beta-\log \gamma+\frac{\log R^{m}-\rho_{\pi} \log \pi}{\rho_{\pi}+1}\right)$ and $\kappa_{5}=\exp \left(-\frac{\left(\rho_{\pi}+2\right)\left(\log R^{m}-\rho_{\pi} \log \pi\right)+\left(\rho_{\pi}+1\right)(\log \beta-\log \gamma)}{\left(\rho_{\pi}+1\right)^{2}}\right)$. We now solve for the bond rate, which satisfies (15) or

$$
R_{t}=\frac{E_{t} c_{t+1}^{-\sigma} \pi_{t+1}^{-1}}{E_{t}\left[\left(R_{t+1}^{m}\right)^{-1} c_{t+1}^{-\sigma} \pi_{t+1}^{-1}\right]} .
$$


Using the solutions for inflation and bonds (54)-(55), we get for the terms on the RHS of (56):

$$
\begin{aligned}
& E_{t}\left(c_{t+1}^{-\sigma} / \pi_{t+1}\right) \\
= & \left(R^{m} / \pi^{\rho_{\pi}}\right)^{\sigma} a_{t}^{-1}\left(\kappa_{5}\right)^{\sigma \rho_{\pi}+\sigma-1}\left(\kappa_{4}\right)^{-\frac{1}{1+\rho_{\pi}}} e^{(1 / 2) \operatorname{var}_{t}\left(\log a_{t+1}\right)\left((\sigma-1)\left(\sigma+2 \sigma \rho_{\pi}+\sigma \rho_{\pi}^{2}-1\right)\right),} \\
& E_{t}\left[\left(1 / R_{t+1}^{m}\right)\left(c_{t+1}^{-\sigma} / \pi_{t+1}\right)\right] \\
= & \left(R^{m} / \pi^{\rho_{\pi}}\right)^{\sigma-1} a_{t}^{-\left(1+\rho_{\pi}\right)} \kappa_{4}^{-1} \kappa_{5}^{\left(\rho_{\pi}+1\right)(\sigma-1)} e^{(1 / 2)\left(\left((\sigma-1)\left(1+\rho_{\pi}\right)\right)^{2}-\sigma \rho_{\pi}^{2}\right) \operatorname{var}_{t}\left(\log a_{t+1}\right)},
\end{aligned}
$$

Using these expressions and simplifying, leads to the following solution for the bond rate

$$
R_{t}=a_{t}^{\rho_{\pi}} \cdot \exp \left[\rho_{\pi}\left(2 \sigma-\rho_{\pi}+2 \sigma \rho_{\pi}-2\right)(1 / 2) \operatorname{var}_{t}\left(\log a_{t+1}\right)\right] \cdot\left(R^{m}\right)^{\frac{1}{\rho_{\pi}+1}} \pi^{-\frac{\rho_{\pi}}{\rho_{\pi}+1}} .
$$

Taking unconditional expectations $\left(E_{0}\right)$ and using that $E_{0} a_{t}^{\rho_{\pi}}=\exp \rho_{\pi}^{2}(1 / 2) v a r_{t}\left(\log a_{t+1}\right)=$ $\exp \rho_{\pi}^{2}(1 / 2) \operatorname{var}\left(\varepsilon_{t}^{a}\right)$ for $\rho^{a}=0$, the mean of the bond rate is given by

$$
E_{0} R_{t}=\exp \left[\rho_{\pi}\left(\sigma \rho_{\pi}+\sigma-1\right) \operatorname{var}\left(\varepsilon_{t}^{a}\right)\right] \cdot\left(R^{m}\right)^{\frac{1}{\rho_{\pi}+1}} \pi^{-\frac{\rho_{\pi}}{\rho_{\pi}+1}},
$$

and thus increases with $\operatorname{var}\left(\varepsilon_{t}^{a}\right)$ and $\sigma$, which establishes the claims made in the proposition.

\subsection{Parameter values}

Table A1: Benchmark parameter values

\begin{tabular}{lll}
\hline \hline Parameter & & Benchmark values \\
\hline$\sigma$ & Relative risk aversion & 2 \\
$n$ & Labor in steady state & $1 / 3$ \\
$\beta$ & Discount factor & 0.984 \\
$\pi$ & Inflation target & 1.0108 \\
$\epsilon$ & Substitution elasticity & 6 \\
$\phi$ & Price rigidity & 0.8 \\
$\alpha$ & Labor income share & $2 / 3$ \\
$s$ & Steady state spread & 0.0115 \\
$\Omega$ & Share of repos & 1.5 \\
$\rho_{a}$ & Autocorreletation & 0.856 \\
$s t . d e v\left(\varepsilon_{a}\right)$ & Standard deviation & 0.0064 \\
$\rho_{R}$ & Autocorreletation & 0.84 \\
$\rho_{\pi}$ & Inflation feedback & 2.37 \\
$\rho_{y}$ & Output feedback & 0.02 \\
$s t . d e v .\left(\varepsilon_{R}\right)$ & Standard deviation & 0.0015 \\
\hline \hline
\end{tabular}




\section{Swiss National Bank Working Papers published since 2004:}

2004-1 Samuel Reynard: Financial Market Participation and the Apparent Instability of Money Demand

2004-2 Urs W. Birchler and Diana Hancock: What Does the Yield on Subordinated Bank Debt Measure?

2005-1 Hasan Bakhshi, Hashmat Khan and Barbara Rudolf: The Phillips curve under state-dependent pricing

2005-2 Andreas M. Fischer: On the Inadequacy of Newswire Reports for Empirical Research on Foreign Exchange Interventions

2006-1 Andreas M. Fischer: Measuring Income Elasticity for Swiss Money Demand: What do the Cantons say about Financial Innovation?

2006-2 Charlotte Christiansen and Angelo Ranaldo: Realized Bond-Stock Correlation: Macroeconomic Announcement Effects

2006-3 Martin Brown and Christian Zehnder: Credit Reporting, Relationship Banking, and Loan Repayment

2006-4 Hansjörg Lehmann and Michael Manz: The Exposure of Swiss Banks to Macroeconomic Shocks - an Empirical Investigation

2006-5 Katrin Assenmacher-Wesche and Stefan Gerlach: Money Growth, Output Gaps and Inflation at Low and High Frequency: Spectral Estimates for Switzerland

2006-6 Marlene Amstad and Andreas M. Fischer: Time-Varying Pass-Through from Import Prices to Consumer Prices: Evidence from an Event Study with Real-Time Data

2006-7 Samuel Reynard: Money and the Great Disinflation

2006-8 Urs W. Birchler and Matteo Facchinetti: Can bank supervisors rely on market data? A critical assessment from a Swiss perspective

2006-9 Petra Gerlach-Kristen: A Two-Pillar Phillips Curve for Switzerland

2006-10 Kevin J. Fox and Mathias Zurlinden: On Understanding Sources of Growth and Output Gaps for Switzerland

2006-11 Angelo Ranaldo: Intraday Market Dynamics Around Public Information Arrivals

2007-1 Andreas M. Fischer, Gulzina Isakova and Ulan Termechikov: Do FX traders in Bishkek have similar perceptions to their London colleagues? Survey evidence of market practitioners' views 
2007-2 Ibrahim Chowdhury and Andreas Schabert: Federal Reserve Policy viewed through a Money Supply Lens

2007-3 Angelo Ranaldo: Segmentation and Time-of-Day Patterns in Foreign Exchange Markets

2007-4 Jürg M. Blum: Why `Basel II’ May Need a Leverage Ratio Restriction

2007-5 Samuel Reynard: Maintaining Low Inflation: Money, Interest Rates, and Policy Stance

2007-6 Rina Rosenblatt-Wisch: Loss Aversion in Aggregate Macroeconomic Time Series

2007-7 Martin Brown, Maria Rueda Maurer, Tamara Pak and Nurlanbek Tynaev: Banking Sector Reform and Interest Rates in Transition Economies: Bank-Level Evidence from Kyrgyzstan

2007-8 Hans-Jürg Büttler: An Orthogonal Polynomial Approach to Estimate the Term Structure of Interest Rates

2007-9 Raphael Auer: The Colonial Origins Of Comparative Development: Comment. A Solution to the Settler Mortality Debate

2007-10 Franziska Bignasca and Enzo Rossi: Applying the Hirose-Kamada filter to Swiss data: Output gap and exchange rate pass-through estimates

2007-11 Angelo Ranaldo and Enzo Rossi: The reaction of asset markets to Swiss National Bank communication

2007-12 Lukas Burkhard and Andreas M. Fischer: Communicating Policy Options at the Zero Bound

2007-13 Katrin Assenmacher-Wesche, Stefan Gerlach, and Toshitaka Sekine: Monetary Factors and Inflation in Japan

2007-14 Jean-Marc Natal and Nicolas Stoffels: Globalization, markups and the natural rate of interest

2007-15 Martin Brown, Tullio Jappelli and Marco Pagano: Information Sharing and Credit: Firm-Level Evidence from Transition Countries

2007-16 Andreas M. Fischer, Matthias Lutz and Manuel Wälti: Who Prices Locally? Survey Evidence of Swiss Exporters

2007-17 Angelo Ranaldo and Paul Söderlind: Safe Haven Currencies 
2008-1 Martin Brown and Christian Zehnder: The Emergence of Information Sharing in Credit Markets

2008-2 Yvan Lengwiler and Carlos Lenz: Intelligible Factors for the Yield Curve

2008-3 Katrin Assenmacher-Wesche and M. Hashem Pesaran: Forecasting the Swiss Economy Using VECX* Models: An Exercise in Forecast Combination Across Models and Observation Windows

2008-4 Maria Clara Rueda Maurer: Foreign bank entry, institutional development and credit access: firm-level evidence from 22 transition countries

2008-5 Marlene Amstad and Andreas M. Fischer: Are Weekly Inflation Forecasts Informative?

2008-6 Raphael Auer and Thomas Chaney: Cost Pass Through in a Competitive Model of Pricing-to-Market

2008-7 Martin Brown, Armin Falk and Ernst Fehr: Competition and Relational Contracts: The Role of Unemployment as a Disciplinary Device

2008-8 Raphael Auer: The Colonial and Geographic Origins of Comparative Development

2008-9 Andreas M. Fischer and Angelo Ranaldo: Does F0MC News Increase Global FX Trading?

2008-10 Charlotte Christiansen and Angelo Ranaldo: Extreme Coexceedances in New EU Member States' Stock Markets

2008-11 Barbara Rudolf and Mathias Zurlinden: Measuring capital stocks and capital services in Switzerland

2008-12 Philip Sauré: How to Use Industrial Policy to Sustain Trade Agreements

2008-13 Thomas Bolli and Mathias Zurlinden: Measuring growth of labour quality and the quality-adjusted unemployment rate in Switzerland

2008-14 Samuel Reynard: What Drives the Swiss Franc?

2008-15 Daniel Kaufmann: Price-Setting Behaviour in Switzerland - Evidence from CPI Micro Data

2008-16 Katrin Assenmacher-Wesche and Stefan Gerlach: Financial Structure and the Impact of Monetary Policy on Asset Prices

2008-17 Ernst Fehr, Martin Brown and Christian Zehnder: On Reputation: A Microfoundation of Contract Enforcement and Price Rigidity 
2008-18 Raphael Auer and Andreas M. Fischer: The Effect of Low-Wage Import Competition on U.S. Inflationary Pressure

2008-19 Christian Beer, Steven Ongena and Marcel Peter: Borrowing in Foreign Currency: Austrian Households as Carry Traders

2009-1 Thomas Bolli and Mathias Zurlinden: Measurement of labor quality growth caused by unobservable characteristics

2009-2 Martin Brown, Steven Ongena and Pinar Yeșin: Foreign Currency Borrowing by Small Firms

2009-3 Matteo Bonato, Massimiliano Caporin and Angelo Ranaldo: Forecasting realized (co)variances with a block structure Wishart autoregressive model

2009-4 Paul Söderlind: Inflation Risk Premia and Survey Evidence on Macroeconomic Uncertainty

2009-5 Christian Hott: Explaining House Price Fluctuations

2009-6 Sarah M. Lein and Eva Köberl: Capacity Utilisation, Constraints and Price Adjustments under the Microscope

2009-7 Philipp Haene and Andy Sturm: Optimal Central Counterparty Risk Management

2009-8 Christian Hott: Banks and Real Estate Prices

2009-9 Terhi Jokipii and Alistair Milne: Bank Capital Buffer and Risk Adjustment Decisions

2009-10 Philip Sauré: Bounded Love of Variety and Patterns of Trade

2009-11 Nicole Allenspach: Banking and Transparency: Is More Information Always Better?

2009-12 Philip Sauré and Hosny Zoabi: Effects of Trade on Female Labor Force Participation

2009-13 Barbara Rudolf and Mathias Zurlinden: Productivity and economic growth in Switzerland 1991-2005

2009-14 Sébastien Kraenzlin and Martin Schlegel: Bidding Behavior in the SNB's Repo Auctions

2009-15 Martin Schlegel and Sébastien Kraenzlin: Demand for Reserves and the Central Bank's Management of Interest Rates

2009-16 Carlos Lenz and Marcel Savioz: Monetary determinants of the Swiss franc 
2010-1 Charlotte Christiansen, Angelo Ranaldo and Paul Söderlind: The Time-Varying Systematic Risk of Carry Trade Strategies

2010-2 Daniel Kaufmann: The Timing of Price Changes and the Role of Heterogeneity

2010-3 Loriano Mancini, Angelo Ranaldo and Jan Wrampelmeyer: Liquidity in the Foreign Exchange Market: Measurement, Commonality, and Risk Premiums

2010-4 Samuel Reynard and Andreas Schabert: Modeling Monetary Policy 
Swiss National Bank Working Papers are also available at www.snb.ch, section Publications/Research Subscriptions or individual issues can be ordered at Swiss National Bank, Fraumünsterstrasse 8, CH-8022 Zurich, fax+41 4463181 14, E-mail library@snb.ch 